\title{
Adaptation of a highly compressible elastomeric material model to simulate compressed expanded graphite and its application in the optimization of a graphite-metallic structure
}

\author{
Przemysław Jaszak ${ }^{1}$ (D)
}

Received: 13 June 2019 / Accepted: 23 March 2020 / Published online: 8 April 2020

(c) The Author(s) 2020

\begin{abstract}
The paper presents simulations of mechanical properties of compressed expanded graphite. To model the stress and strain states of compressed expanded graphite, a hyperelastic material model formulated by the Blatz-Ko was adapted. The idea of using this model resulted from the assumptions that compressed expanded graphite exhibits similar mechanical properties to polyurethane foam with high density. The material constant of the Blatz-Ko model was determined by numerical calculations where deformation energy equation was parameterized with the shear modulus. Such material model used in a compressed expanded graphite simulation was experimentally validated. Subsequently, the Blatz-Ko model was used in a numerical simulation of the graphite-metallic structure in the form of a spiral wound gasket which is composed of metallic and elastic tapes. This structure was subjected to an optimization process which included the reduction of stress in the elastic graphite tape obtaining the appropriate axial stiffness of the gasket. In the final stage, the optimal design of the gasket was experimentally tested. The experimental results were compared with the data obtained numerically, which allowed to verify the adapted material model and boundary conditions of the numerical gasket model.
\end{abstract}

Keywords Compressed expanded graphite $\cdot$ Spiral wound gasket $\cdot$ Stiffness optimization $\cdot$ Highly compressible material

$\begin{array}{ll}\text { Abbreviations } \\ \text { NG } & \text { Natural graphite } \\ \text { EG } & \text { Expanded graphite, } \\ \text { CEG } & \text { Compressed expanded graphite } \\ \text { PUF } & \text { Polyurethane foam } \\ \text { SWG } & \text { Spiral wound gasket } \\ \text { FEM } & \text { Finite element method } \\ \text { B-K } & \text { Blatz-Ko material model }\end{array}$

\section{Introduction}

Expanded graphite $(\mathrm{EG})$ is a material produced from natural graphite (NG) in a chemical and thermal process called exfoliation [1]. Due to this process, its volume increases even up

Technical Editor: Paulo de Tarso Rocha de Mendonça, Ph.D.

Przemysław Jaszak

przemyslaw.jaszak@pwr.edu.pl

1 Department of Power Engineering, Wroclaw University of Science and Technology, Street Wybrzeże S. Wyspiańskiego, 27, Wroclaw, Poland to 400 times. EG is widely used as an addition to various types of nano-composites [2-7]. It inherited lots of favorable features of NG, i.e., it exhibits high chemical and thermal resistance $[8,9]$. Paper $[10]$ presents an innovative investigation method and test results concerning elastic properties of EG. As it was found, EG's elastic modulus strongly depends on the direction of measurement. For instance, the value in-plane of compression is bigger than values measured outof-plane at the same density level. The mechanical, electrical and chemical properties of EG were presented in [11]. In accordance with an experimental test, it was proved that all properties of EG can be approximated by means of the power law. The most popular form of EG used in industry is compressed expanded graphite (CEG). It characterizes with high mechanical strength, especially at a compression load [12]. Due to these properties, CEG can be utilized in various industrial applications [13]. Good elasticity and low permeability of fluids caused that CEG is widely used in sealing technology [14]. In industry CEG is utilized as thin, laminated foil with bulk density ranging from 0.5 to $1.5 \mathrm{~g} /$ $\mathrm{cm}^{3}$. Its drawbacks are big losses of mass in contact with oxygen, especially at an elevated temperature. The degree of CEG oxidation depends on its purity, particularly on sulfur 
contents, which is usually in a range from 300 to $1000 \mathrm{ppm}$. Mechanical strength, in case of a tensile load, is low and ranges from 2 to $6 \mathrm{MPa}$ [12]. In case of a compression load, the destructive contact pressure of CEG's laminated foil is (depending on foil thickness) from $180 \mathrm{MPa}$ (at thickness $1 \mathrm{~mm}$ ) to $300 \mathrm{MPa}$ (at thickness $0.35 \mathrm{~mm}$ ). In sealing technology, CEG has found an application as filler used in, so called, semi-metal gaskets of the flange-bolted joints. The most popular form is the spiral wound gasket (SWG). More details concerning this structure were presented in chapter 5 ; however, it is worth to mention its main features. The advantage of SWG is a very small leakage level at relatively low bolts' load $[15,16]$. The quality of a gasket strongly depends on CEG's properties, predominantly on its packing density in the spiral structure $[17,18]$. The main disadvantage is the limited compressive strength, since at an excessive load the internal windings of the spiral could be buckled [19-23]. Another important issue is the gasket's stiffness. In line with the standard ASME 16.20 2017, stiffness should be properly designed depending on the size of the pipe's nominal diameter and the sealing pressure. In order to increase the stiffness, the spiral is wound tighter or embedded in metal rings: internal and/or external ones. The use of these rings and their influence on the gasket's stiffness were presented in [15]. Another solution that enhances stiffness of the gasket is proper shaping of the tape's cross section [24]. The most common tool accelerating the process of the structure optimization is the finite element method (FEM). In case of gaskets' modeling, this method is also used as presented in papers $[25,26]$. The most challenging issue in the numerical modeling of CEG is the proper selection of the material model mapping its elastic behavior. Based on results presented in [27], it was proved that treating CEG as an isotropic, linear material causes a big discrepancy between numerical results and experimental ones. In this paper, the new approach was proposed to reflect elastic properties of CEG by means of a nonlinear material model. Based on the experimental compression test of CEG, it was found that the characteristic describing the relationship between stress-strain could be, with high accuracy, modeled with a nonlinear compressible hyperelastic Blatz-Ko model. In the further step, this model was used in a numerical simulation of the graphite-metallic structure in the form of SWG. This structure was subjected to the optimization process which included stress reduction in the elastic graphite tape and obtaining the appropriate axial stiffness of the gasket.

\section{CEG elastic properties}

The main difference between EG and NG is their internal structure which is presented in Fig. 1. The structure of EG is more porous due to the exfoliation process. When it comes to mechanical properties, NG is an isotropic material and non-compressible, whereas EG exhibits a nonlinear effect with high compressibility and plasticity levels. During the compression of EG, its bulk density increases and as a result the elastic modulus can change even up to several orders of magnitude (Fig. 2).

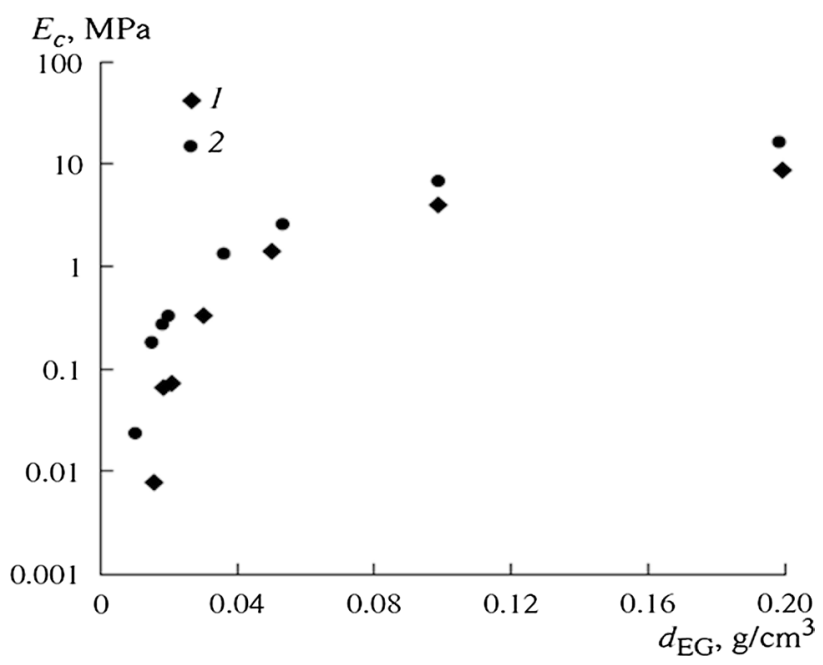

Fig. 2 Elasticity modulus versus bulk density of (EG) [7]
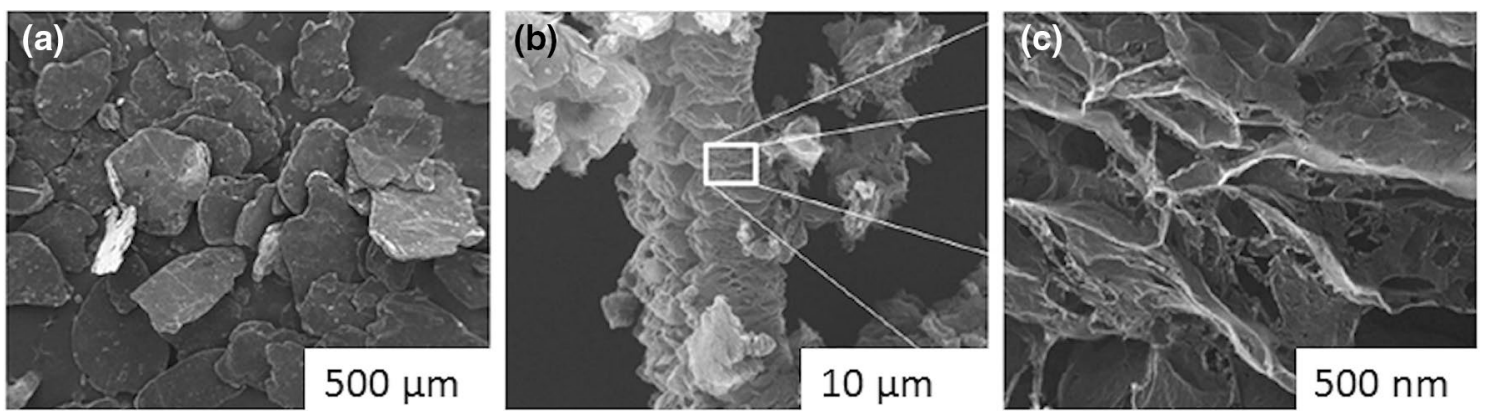

Fig. 1 The internal structure of graphite; a natural graphite, b, c expanded graphite [5] 
The approximate value of CEG elastic modulus at the compression load can be mapped with a great accuracy by means of the empirical Eq. (1) [10].

$E=E_{0}(1-a P)^{n}$

where $E_{0}$ is the elastic modulus at $0 \%$ porosity, $P$ is the porosity level, $a, n$ are the material constants.

High dependence of CEG's elastic modulus on the compression level causes that the use of a constant value to model the stress and strain of the structures made of CEG can lead to large discrepancies between the model and real behavior of the material under load [27]. Nonlinear dependence between the stress and strain of CEG under compression proves that the elastic modulus is strongly progressive. Similar properties exhibit foamed elastomeric materials. The most similar mechanical properties to CEG have materials made of polyurethane foam (PUF) (especially rigid PUF with high bulk density, Fig. 3). Similarities can be found in mechanical properties (Table 1) and in the same course of the curve describing the relationship between stress and strain at the compression load [29-34].

\section{Constitutive material model}

Due to the fact that CEG exhibits similar mechanical properties to PUF, its stress-strain relationship could be treated as a compressible elastomeric material. This statement is only valid at compression strain since, while compressing, both materials exhibit the same forming of the compressive curve. Moreover, elastomeric behavior of CEG in a microscale was proved and described in [35]. The most popular constitutive model reflecting hyperelastic strain behavior of the foamed
Table 1 Comparison of selected physical properties of EG and highand low-density PUF [28-30]

\begin{tabular}{llll}
\hline Material & EG & $\begin{array}{l}\text { Polyurethane foam } \\
\text { at low bulk density }\end{array}$ & $\begin{array}{l}\text { Polyurethane foam } \\
\text { at higher bulk } \\
\text { density }\end{array}$ \\
\hline $\begin{array}{l}\text { Density, } \mathrm{g}^{1} \mathrm{~cm}^{-3} \\
\text { Young module in } \\
\text { plane, MPa }\end{array}$ & 0.2 & 0.08 & 0.28 \\
$\begin{array}{c}\text { Poisson's ratio } \\
\text { pis }\end{array}$ & $0.22 / 0.3$ & 0.0127 & 89 \\
\hline
\end{tabular}

compressible elastomers like PUF was proposed in [36]. Its constitutive equation describes the strain energy stored in a volume of the body under strain. The formula of the strain energy is as follows:

$$
\begin{aligned}
W\left(J_{1}, J_{2}, J_{3}\right)= & \frac{\mu f}{2}\left[\left(J_{1}-3\right)-\frac{2}{q}\left(J_{3}^{q}-1\right)\right] \\
& +\frac{\mu((1-f)}{2}\left[\left(J_{2}-3\right)-\frac{2}{q}\left(J_{3}^{-q}-1\right)\right]
\end{aligned}
$$

where $J_{1}, J_{2}, J_{3}$ are the reduced Cauchy-Green strain invariants:

$J_{1}=\bar{I}_{1}, \quad J_{2}=\frac{\bar{I}_{2}}{\bar{I}_{3}}, \quad J_{3}=\sqrt{\bar{I}_{3}}$

wherein $I_{1}=\lambda_{1}^{2}+\lambda_{2}^{2}+\lambda_{3}^{2}, I_{2}=\lambda_{1}^{2} \lambda_{2}^{2}+\lambda_{2}^{2} \lambda_{3}^{2}+\lambda_{3}^{2} \lambda_{1}^{2}$, $I_{3}=\lambda_{1}^{2} \lambda_{2}^{2} \lambda_{3}^{2}$.

The parameters $\mu$ and $q$ are associated with material constants and are as follows:

$\mu=G, q=\frac{-2 v}{1-2 v}$
Fig. 3 Compressive characteristics of CEG foil and polyurethane foam

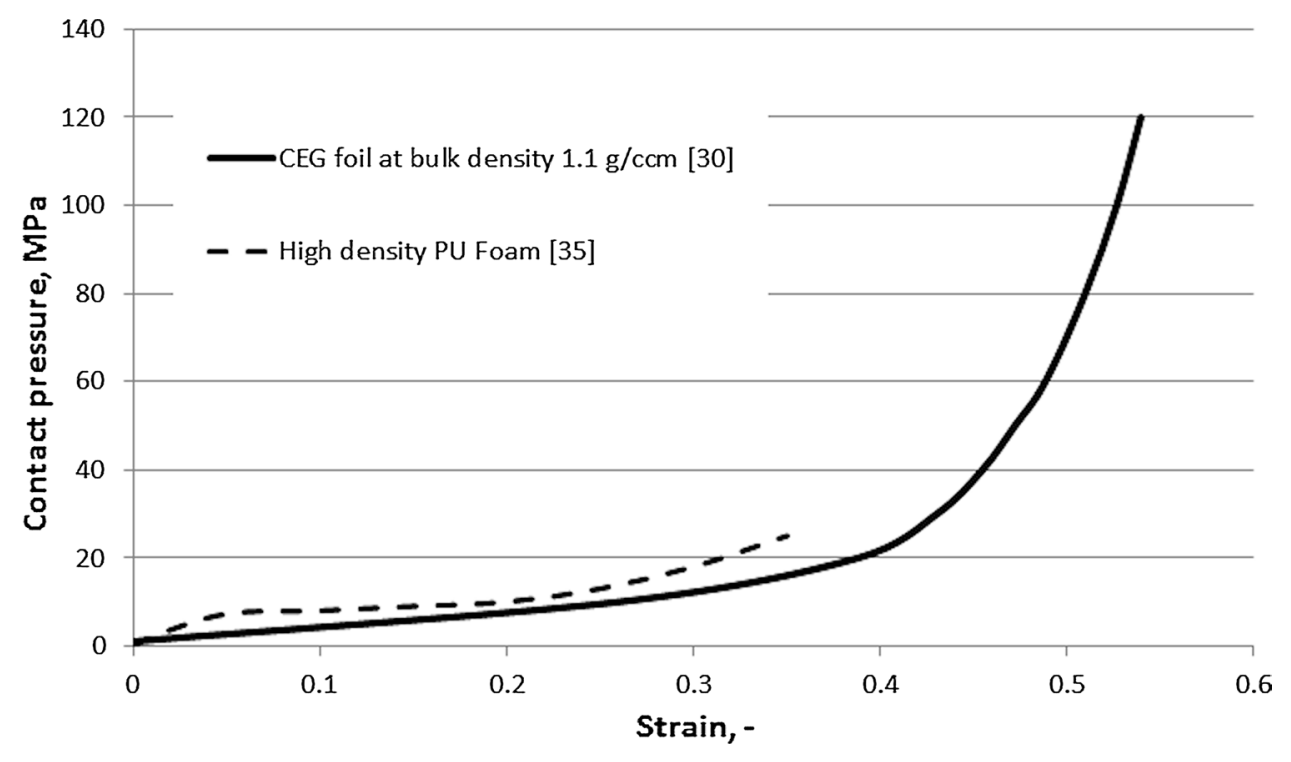


where $G$ is the initial shear modulus (under infinitesimal strain) $N$ is the Poisson's ratio.

A special case of the formula (2) is when $f=0$ or $f=1$. The former case is dedicated to foamed, polyurethane elastomer, and the latter reflects the behavior of solid, polyurethane rubber. For highly compressible materials, the parameter $f$ equals 0 , thus the formula (2) reduces to the form:

$W=\frac{G}{2}\left[\left(J_{2}-3\right)-\frac{2}{q}\left(J^{\left(\frac{2 v}{1-2 v}\right)}-1\right)\right]$.

Additionally, assuming that Poisson's ratio of polyurethane elastomeric foam equals 0.25 , and using the relation (3), the strain energy function can be expressed as:

$W=\frac{1}{2} G\left(\frac{\overline{I_{2}}}{\overline{I_{3}}}+2 \sqrt{\bar{I}_{3}}-5\right)$.

Based on Eq. (6), stress can be calculated as:

$\sigma_{i j}=\frac{\partial W}{\partial \varepsilon_{i j}}=2 \frac{\partial W}{\partial C_{i j}}$

where $\sigma_{i j}$ is the components of the Cauchy stress tensor, $\varepsilon_{i j}$ the component of the Cauchy strain tensor, $C_{i j}$ the component of the right Green-Cauchy deformation tensor $\mathrm{C}_{i j}=\mathrm{f}\left(I_{1}\right.$, $\left.I_{2}, I_{3}\right)$.

In order to adopt the formula (6) to simulate CEG's compression, the following assumptions of its properties have to be defined:

- Is an isotropic material,

- Has no plastic deformation,

- Is fully reversible,

- Has no ability to dissipate energy.

\section{Simulation of CEG compression}

The simulation of CEG's compression was carried out by means of numerical calculations based on FEM. The discrete model in the form of two steel plates and a CEG's disk located between them are shown in Fig. 4.

The plates were assigned as elastic properties of stainless steel with the elastic modulus $E=200,000 \mathrm{MPa}$ and Poisson's ratio $v=0.3$, while the disk material was described by Eq. (6). The numerical model was prepared as an 3-D object discretized with SOLID 186 finite elements with a highorder shape function. In order to eliminate the numerical errors, the mesh's density of the CEG's disk was $0.4 \mathrm{~mm}$. Further reduction in the size of the mesh had no influence on the numerical results. In accordance with Fig. 4, the lower plate was fixed, whereas the upper one was set as movable in an axial direction. In order to simulate CEG's compression, the upper plate was simulated as movable in the z-direction. The contact area between the plates and the disk was discretized with CONTA 174 and TARGET 170 element with a friction coefficient 0.4 . The simulation included compressing the disk by moving the upper plate up to the maximum value $U_{\mathrm{z}}=0.7 \mathrm{~mm}$. The numerical issue was formulated as static with an active function of the material nonlinearity and the function of large displacements. The equilibrium equation of the motion in the numerical model was formulated as [37]:

${ }^{t} K_{\mathrm{T}} \Delta U=\left(K_{0}+K_{\mathrm{d}}+K_{\sigma}\right) \Delta U=\Delta F$

where $K_{\mathrm{T}}$ is the tangent stiffness matrix, $K_{0}$ is the usual small displacement stiffness matrix, $K_{\mathrm{d}}$ is the large displacement stiffness matrix, $K_{\sigma}$ is the initial stress matrix dependent on the stress level, $\Delta U$ is the generalized displacement vector
Fig. 4 Discrete model of the disk compression

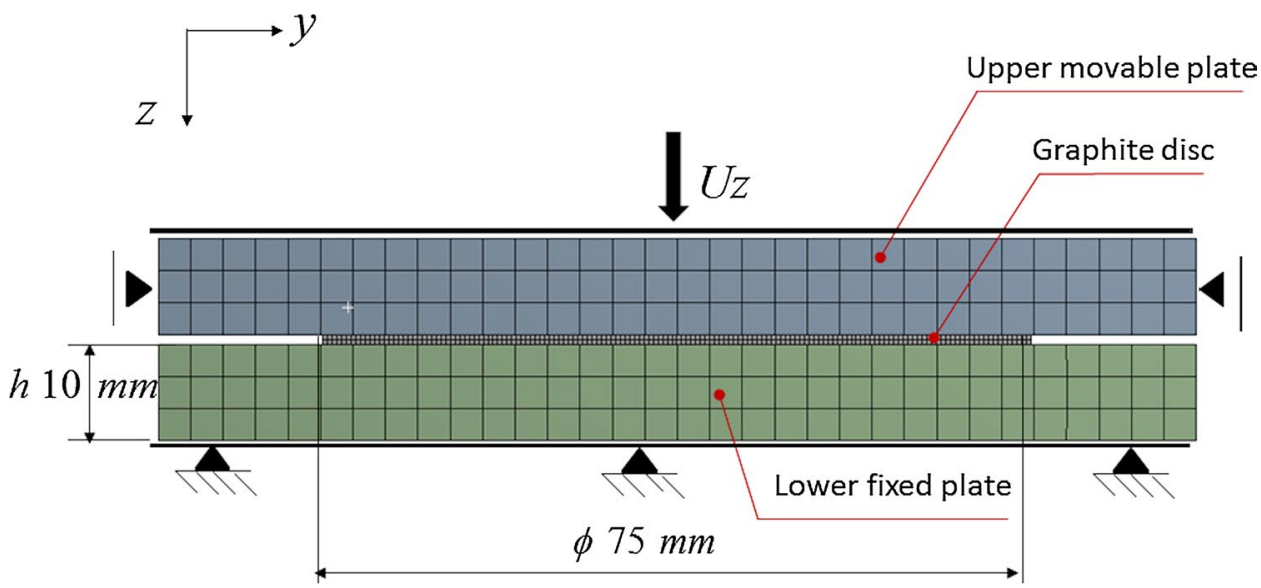


and $\Delta F$ is the difference between the applied and the resistant forces. The particular stiffness matrices are as follows:

$K_{0}=\int_{V_{0}} B_{0}^{T} D B_{0} \mathrm{~d} V_{0}$

$K_{\mathrm{d}}=\int_{V_{0}}\left(B_{0}^{T} D B_{\mathrm{L}}+B_{\mathrm{L}}^{T} D B_{0}+B_{\mathrm{L}}^{T} D B_{\mathrm{L}}\right) \mathrm{d} V_{0}$

$K_{\sigma}=\int_{V_{0}}\left(B_{\mathrm{N}}^{T} S B_{\mathrm{N}}\right) \mathrm{d} V_{0}$

where $B_{0}$ is linear strain-displacement transformation matrix used in a linear infinitesimal strain analysis, $B_{\mathrm{L}}$ is linear strain-displacement transformation matrix which depends on displacement, $B_{\mathrm{N}}$ is the nonlinear strain-displacement transformation matrix, $D$ is the elasticity matrix and $S$ is the tensor of the second Piola-Kirchhoff stress.

The results were presented in the form of characteristics describing the reaction force of the upper plate as a function of its displacement. The values of the initial shear modulus $G$, which was the parameter of Eq. (6), were taken from the range from 10 to $20 \mathrm{MPa}$. Equation (8) was solved by means of the Newton-Raphson incremental method [38] using the commercial software ANSYS 18.0. Figure 5 presents the results of the computations at different values of the shear modulus $G$.

\section{Verification of numerical calculations}

Numerical calculations were verified by an experimental study. The tests included compressing a graphite disk with a diameter of $75 \mathrm{~mm}$ and thickness of $1 \mathrm{~mm}$, which was cut from CEG foil with bulk density of $0.8 \mathrm{~g} / \mathrm{cm}^{3}$. Figure 6 presents the test rig. Its main element was a computer-controlled hydraulic press equipped with force sensors (mounted in the upper plate of the press) and displacement sensors.

The computer connected to the press registered the relationship between the compressive force of the disk and its axial displacement. Figure 7 shows the compression characteristic obtained experimentally on the background of the characteristic obtained in a numerical way. The experimental characteristic presents the average value obtained from three tests. Based on the results, it can be concluded that the material model (6) adapted to simulate CEG's compression reflects its compression behavior with great accuracy. The most accurate mapping of the experimental characteristic with the numerical model was obtained at the shear modulus $G=15 \mathrm{MPa}$.

\section{Modeling of CEG-metal structure and its optimization}

\subsection{Spiral wound gasket (SWG)}

As mentioned in the introduction, the industrial applications of the structures consisting of CEG and metal are widely used as gaskets operating in bolted-flange joints.
Fig. 5 Comparison of reaction force versus compression obtained from numerical calculations at different $G$ values

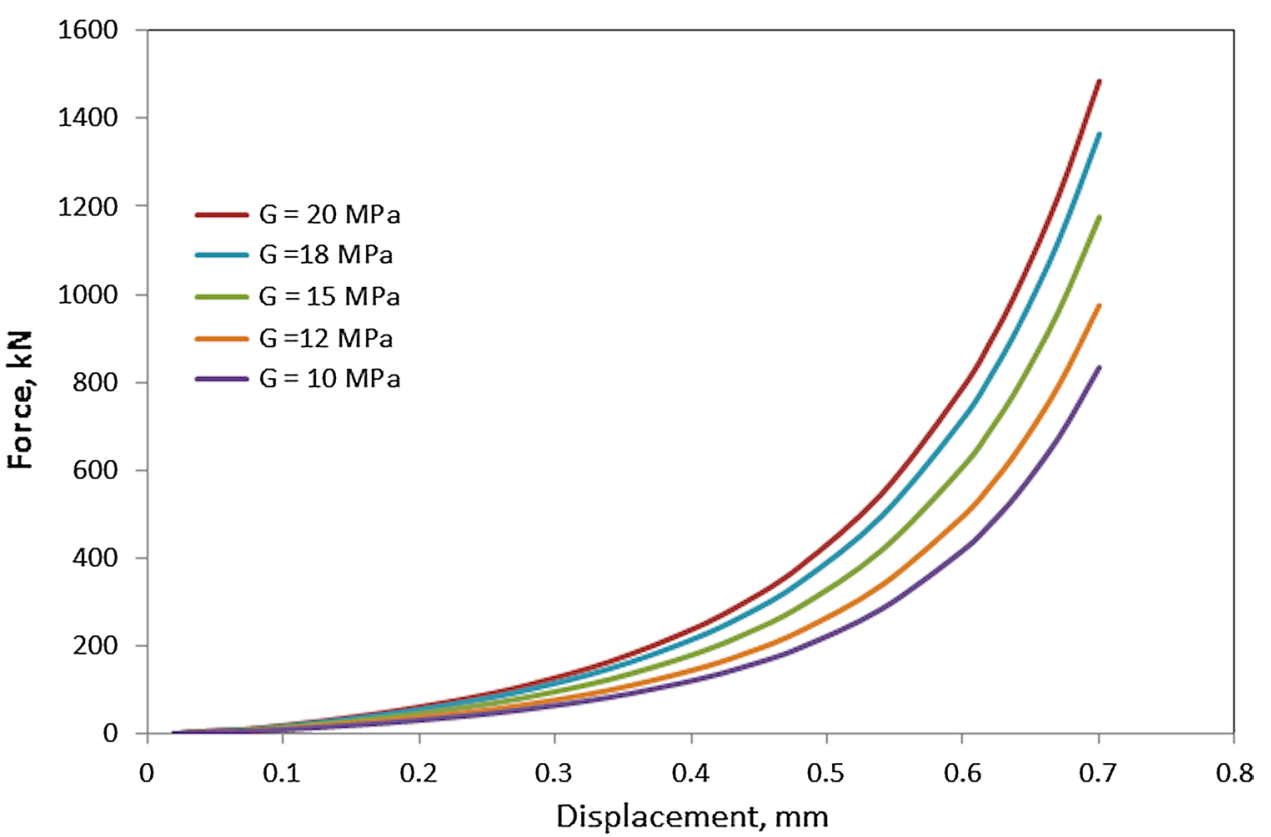


Fig. 6 Test rig for determining compression characteristics of CEG
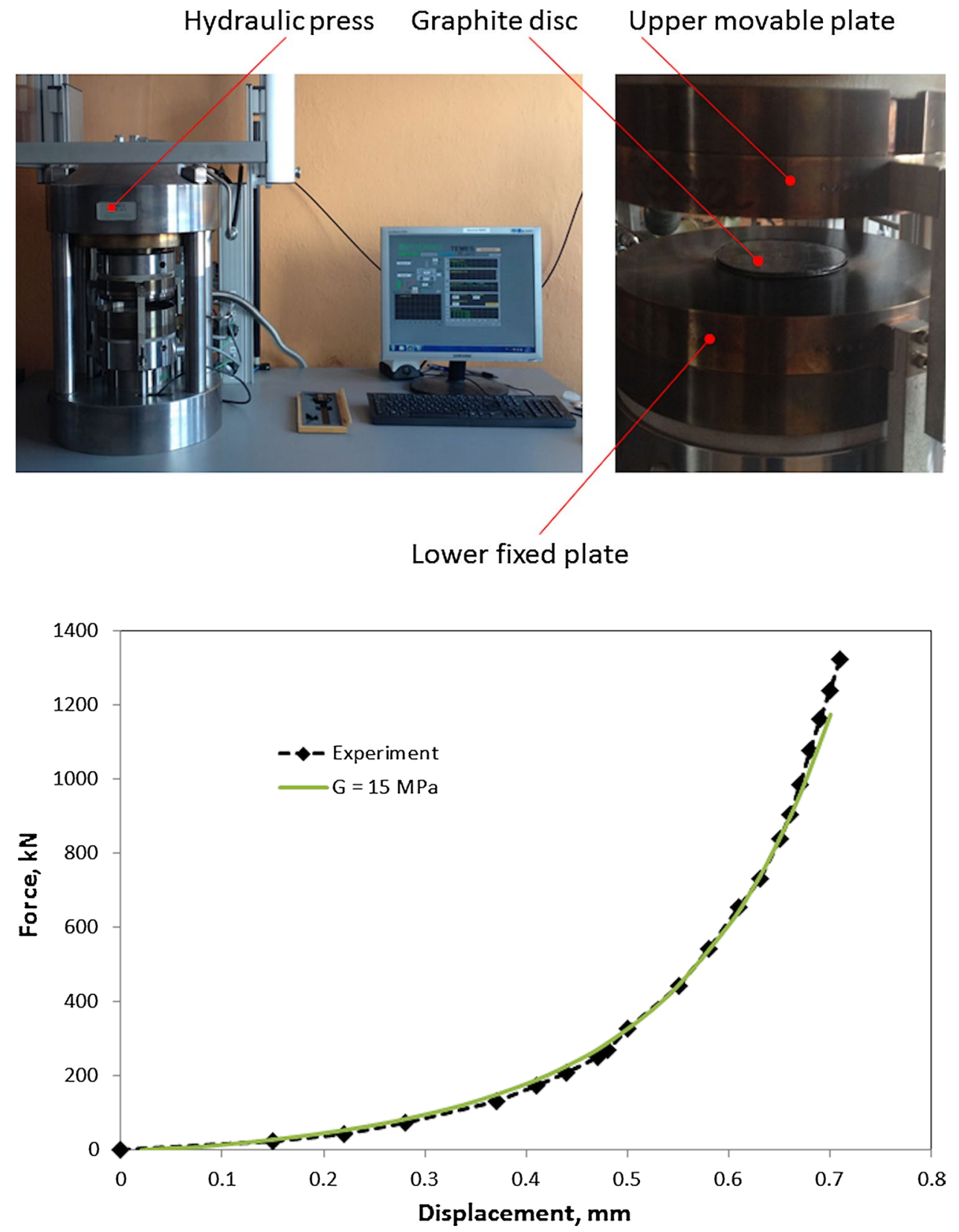

Fig. 7 The experimental compression curve of CEG on the background of numerical characteristic as described in [19]. According to the standard EN 125602, four basic types of SWG solutions can be distinguished:

- windings only-Fig. 9a,

- windings with an internal ring-Fig. 9b,

- windings with an outer ring-Fig. 9c,

- windings with inner and outer rings-Fig. 9d.

Each solution is dedicated to a specific shape of a flange's face, which is schematically presented in Fig. 10. Generally, the gasket presented in Fig. 9a is used in a tongue-groove flange type (Fig. 10b) or spigot-recess flanges (Fig. 10c), 
Fig. 8 Structure of the spiral wound gasket SWG

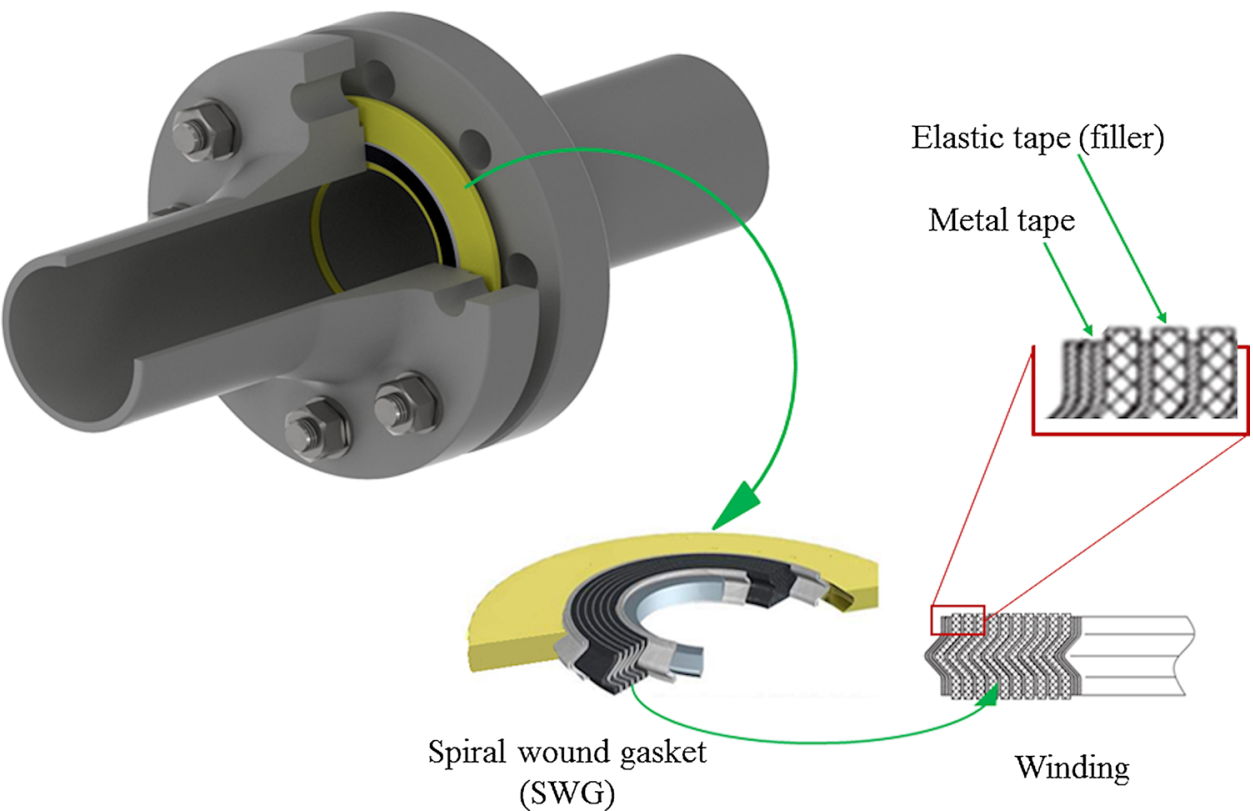

(SWG)

(a)

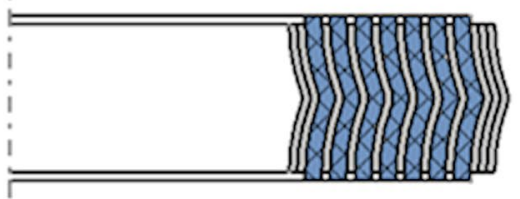

(c)

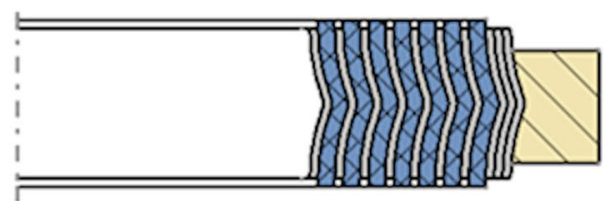

(b)

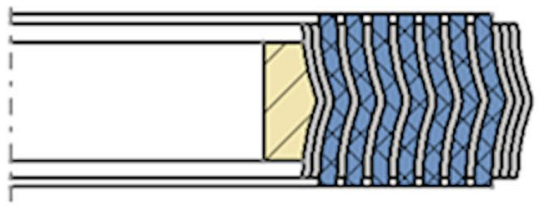

(d)

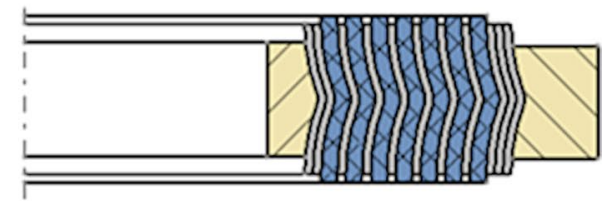

where functions of the metal rings are provided by a properly shaped flange's face.

Nevertheless, there are exceptions (due to economic reasons) where SWG presented in Fig. 9a is used in flat faces or raised faces of the flange joints. This solution is characterized by very low axial stiffness which could lead to an excessive radial deformation of the internal part of gasket's windings, which, as a result, causes its inward buckling [20-23]. On the other hand, increased stiffness of SWG (resulting from embedding the windings in the metal rings) can lead to excessive stress of the elastic filler and its destruction or may also cause leakage growth [39]. In accordance with the standard EN 12560-2, the axial stiffness of SWG is strictly defined and it is assumed that with a bolt root stress
$197 \mathrm{MPa}$ or $207 \mathrm{MPa}$ (depending on the flange nominal size and pressure class) the gasket should be compressed at least $20 \%$ of its initial height. The required stiffness (except for the embedded windings in the metal rings) can be achieved by means of stiffer filler (usually PTFE) or tighter winding of the tapes during the forming process [17].

According to the author's assumption, an additional feature that can significantly influence the axial stiffness of the windings is appropriate shaping of the tapes during the production process. Therefore, in the following part of the work the process of the gasket's optimization was carried out. It was considered that proper shaping of the metal tape leads to stress minimization in the elastic tape as well as provides the required gasket's stiffness. 

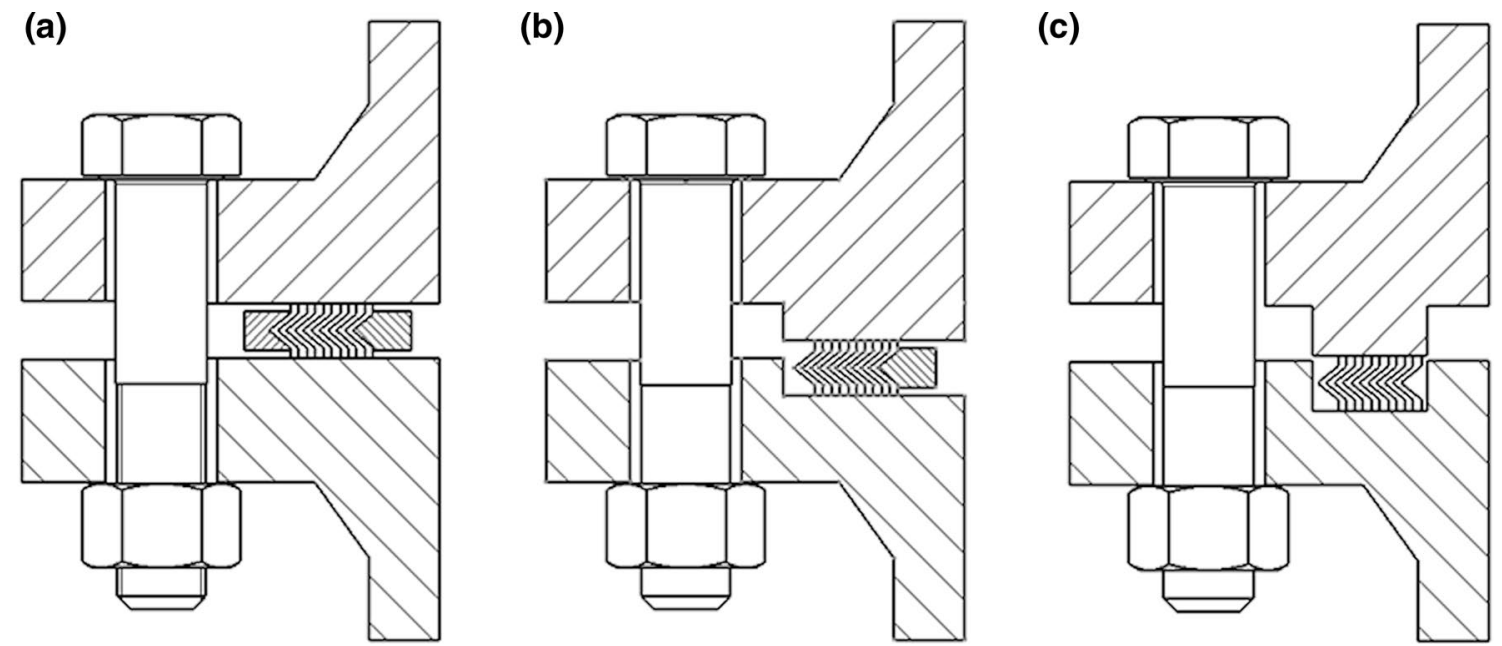

Fig. 10 Example of the flanges' face solutions cooperating with given types of (SWG); a flat or raised face for gasket with two rings, b spigotrecess faces for gasket with an inner ring, $\mathbf{c}$ groove-tongue faces for windings only

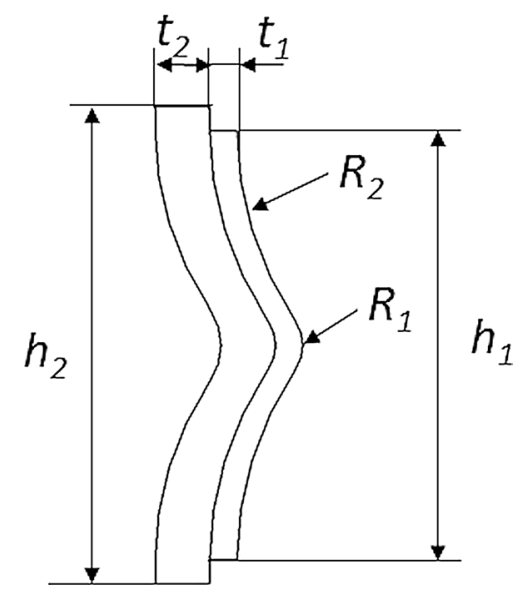

Fig. 11 Geometrical features of metal and elastic tapes

\subsection{Optimization formulation}

The standardized PN40 DN40 SWG without metal rings was subjected to an optimization process. The PN40 DN40 (nominal diameter $1^{1 / 2}$,, pressure class 600 ) corresponds to dimensions of the standard gasket used in the tests, according to the European standard EN 13555. The set of parameters describing geometrical features of the tapes' shape in accordance with Fig. 11 were as follows: radii of the metal tape $R_{1}$ and $R_{2}$, height of the metal tape $h_{1}$, height of the elastic tape $h_{2}$, thickness of the metal tape $t_{1}$, thickness of the elastic tape $t_{2}$. The material features stated as $e_{1}$ corresponded to the material properties of austenitic steel of the metal tape and $e_{2}$ corresponded to the material properties of CEG for the elastic tape. A set of all the described parameters of the gasket's features were collected below: $\mathbf{d}=\left\{h_{1} ; h_{2} ; t_{1} ; t_{2} ; R_{1} ; R_{2} ; e_{1} ; e_{2}\right\}$.

The radii $R_{1}$ and $R_{2}$ were assumed to be variable (decisive) parameters:

$\mathbf{s}=\left\{R_{1} ; R_{2}\right\}$

where $R_{1} \in\{0.5 ; 2 ; 4 ; 8 ; 16\} \mathrm{mm}$ and $R_{2} \in\{2 ; 4 ; 8 ; 16\} \mathrm{mm}$.

Constant parameters were: $h_{1}=4.0 \mathrm{~mm}, h_{2}=4.5$, $t_{1}=0.2 \mathrm{~mm}, t_{2}=0.7 \mathrm{~mm}$, material of the metal tape $e_{1}$ steel $316 \mathrm{~L}$, material of the elastic tape $e_{2}-\mathrm{CEG}$ at bulk density $0.8 \mathrm{~g} / \mathrm{cm}^{3}$. Based on enforced conditions, an optimal design of the gasket should meet the basic criterion of achieving $20 \%$ strain of the initial gasket's height under the bolt root stress $207 \mathrm{MPa}$ and, what is more important, the strain should not cause destruction of the elastic tape. The value of bolt root stress $207 \mathrm{MPa}$ in relation to the bolt dimensions of the flange joint DN40 PN40 generates pressure on the gasket's top surface $p=80 \mathrm{MPa}$. Therefore, the criterion of optimization was formulated as follows: Find such a set of variable parameters $\left(R_{1}, R_{2}\right)$, at which the equivalent stress in the elastic tape $\sigma(s)$ will be minimal under windings' strain $20 \%$ and, thus, the gasket's contact pressure for this condition should be greater than $p$ $(s)>80 \mathrm{MPa}$. Hence, the objective function was formulated as follows:

$\sigma(s ; \varepsilon)=\min$.

The first imposed constraint was:

$p\left(s ; \varepsilon_{\lim }\right) \geq 80 \mathrm{MPa}$ where $\varepsilon_{\lim }=20 \%$. 
Due to the fact that the permissible compression stress of CEG should not be exceeded, the stress in the elastic tape was imposed as a second constraint:

$g(s ; \varepsilon)=\sigma_{\max } \leq \sigma_{\text {permis. }}=180 \mathrm{MPa}$.

An additional constraint in the form of (17) was introduced in order to avoid the collapse effect of the gasket. A function of the contact pressure versus gasket's strain $p=f(\varepsilon)$ should be progressive in the whole range of the strain:

$h(s ; \varepsilon)=\frac{\mathrm{d} p(s ; \varepsilon)}{\mathrm{d} \varepsilon}>0$.

Ultimately, the objective function and the constraints of the gasket's optimization were as follows:

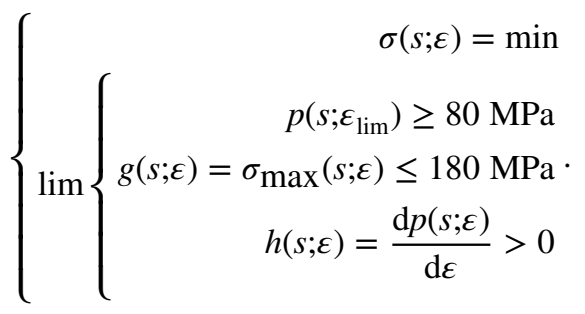

The enforced parameter was strain ranging from 0 to $20 \%$.
$W=\{\varepsilon\}$.

The reaction of computation was in the form of the contact pressure of the windings as well as equivalent stress in the elastic tape:

$R=\left\{\sigma_{\max }(s ; \varepsilon) ; p(s ; \varepsilon)\right\}$.

The set of parameters and reactions of SWG model are shown in Fig. 12.

\subsection{Computational model}

Figure 13 presents the axisymmetric model of the gasket (in configuration $R_{1}=0.5 \mathrm{~mm}, R_{2}=4.0 \mathrm{~mm}$ ) reflecting its location between two plates of the hydraulic press. The simulation included displacement of the upper plate from $U_{\mathrm{z}}=0$ to $0.9 \mathrm{~mm}$, causing compression of the gasket. The value $U_{\mathrm{z}}=0.9 \mathrm{~mm}$ constitutes $20 \%$ of the gasket's strain at its initial height equal $h_{2}=4.5 \mathrm{~mm}$. The lower plate of the model was fixed, whereas the upper one was set as movable in the $\mathrm{z}$-axis direction. The contact area between the metal tapes and filler tapes, as well as between the plates and the gasket's top surfaces, was set as frictional with coefficient 0.4 . The mesh size of the CEG filler was $0.1 \mathrm{~mm}$. The numerical issue
Fig. 12 The set of parameters of SWG computational model

\section{Enforced parameter}

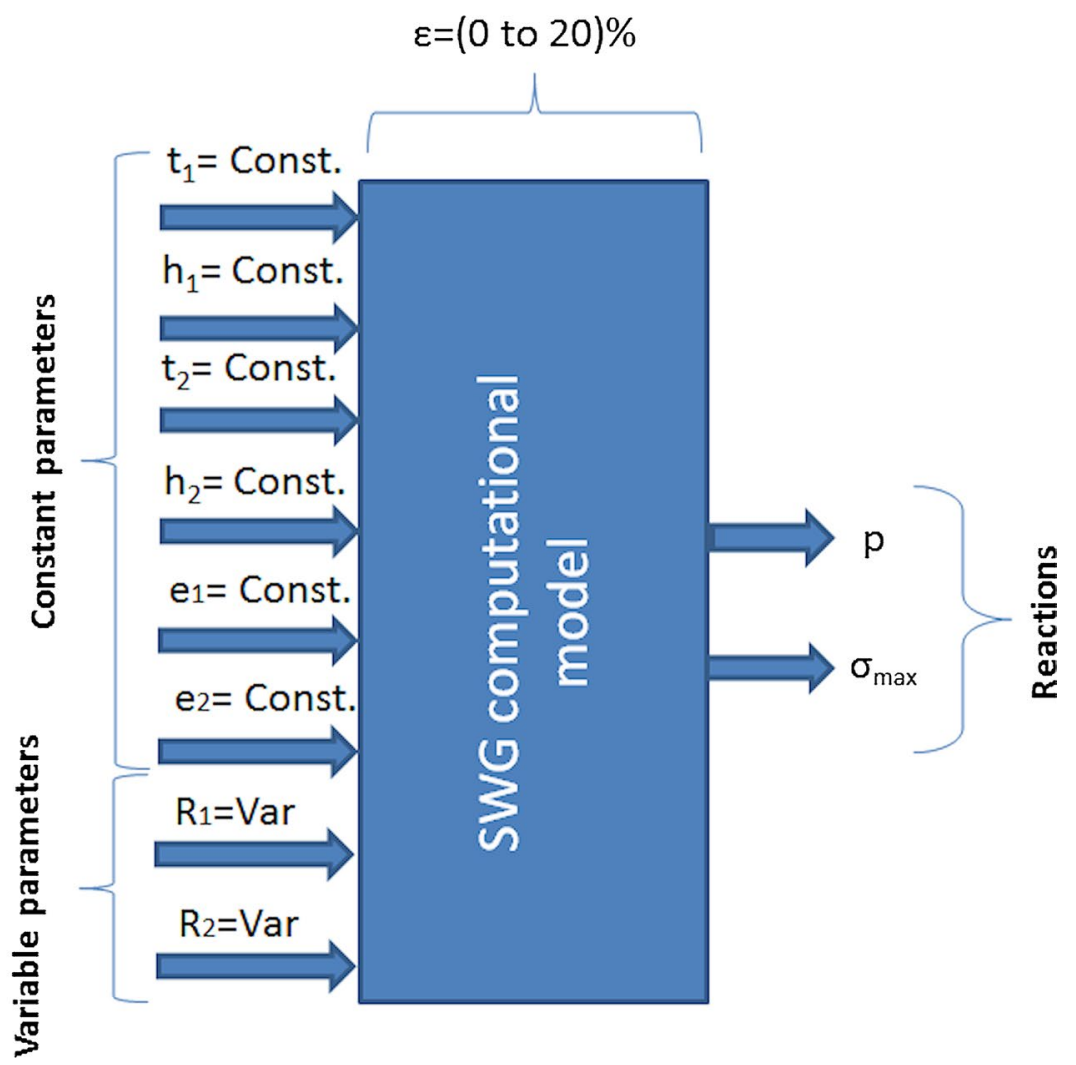


Fig. 13 The axisymmetric numerical model of the windings and plates
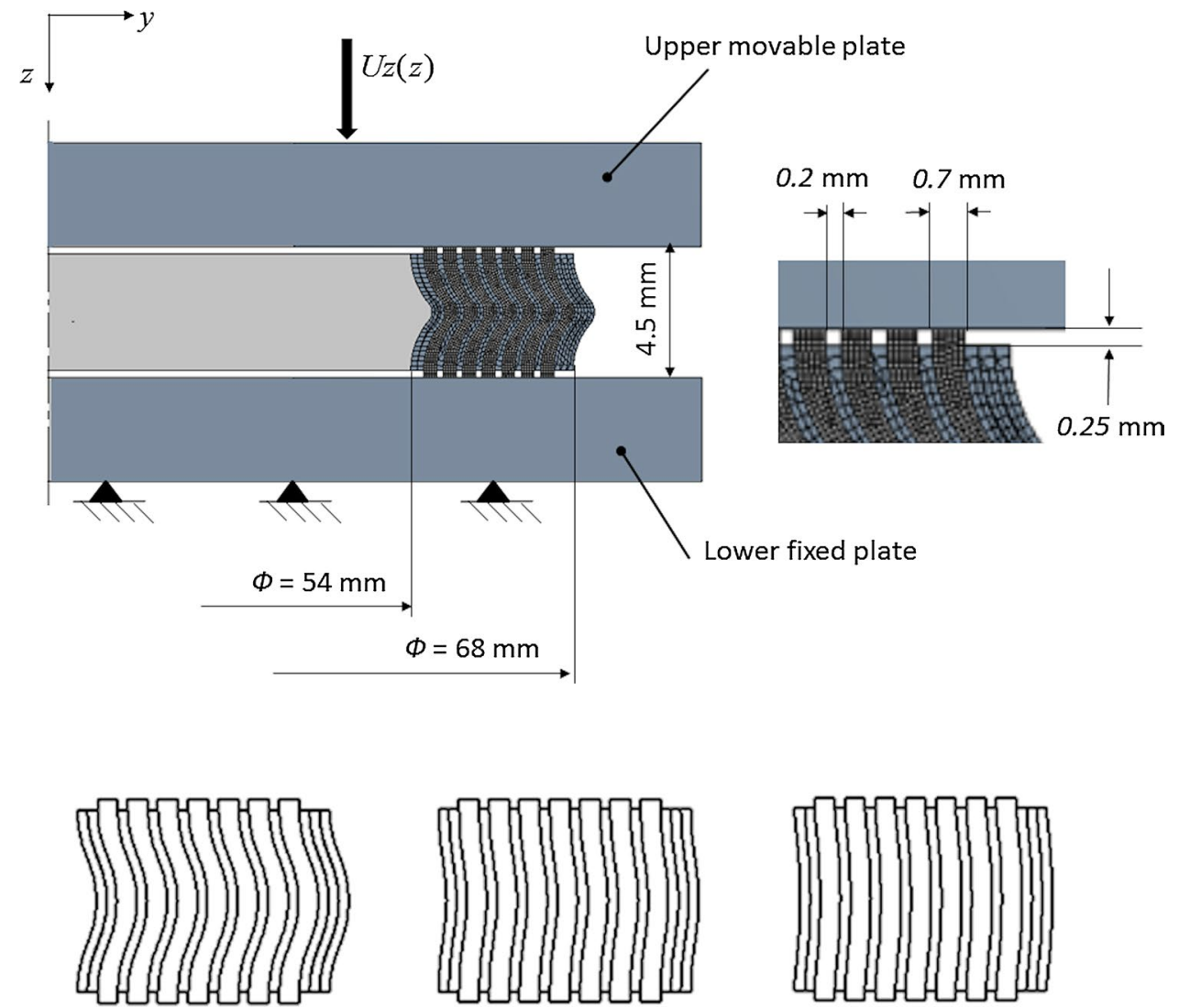

$$
R_{1}=0.5 \mathrm{~mm}
$$$$
R_{1}=2.0 \mathrm{~mm}
$$$$
R_{1}=4.0 \mathrm{~mm}
$$$$
R_{1}=16.0 \mathrm{~mm}
$$$$
R_{2}=2.0 \mathrm{~mm}
$$

$R_{2}=2.0 \mathrm{~mm}$

Fig. 14 Examples of gasket's sections depending on the values of $R_{1}$ and $R_{2}$

Fig. 15 Distribution of the equivalent stress $(\mathrm{MPa})$ in the graphite tape in subsequent deformation steps for the variant profile $R_{1}=0.5 \mathrm{~mm}$ and $R_{2}=2 \mathrm{~mm}$; a compression $0.3 \mathrm{~mm}$, b compression $0.5 \mathrm{~mm}$, c compression $0.7 \mathrm{~mm}$, d compression $0.9 \mathrm{~mm}$ (a)

Compression $0.3 \mathrm{~mm}$

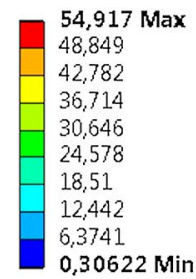

(c)

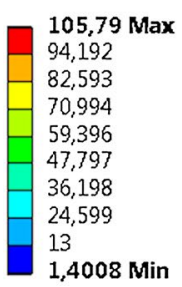

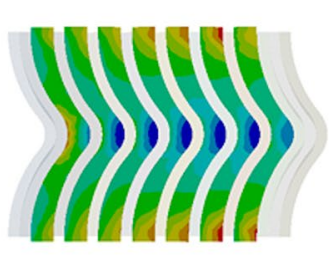

Compression $0.7 \mathrm{~mm}$

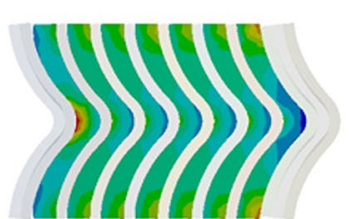

(b) Compression $0.5 \mathrm{~mm}$
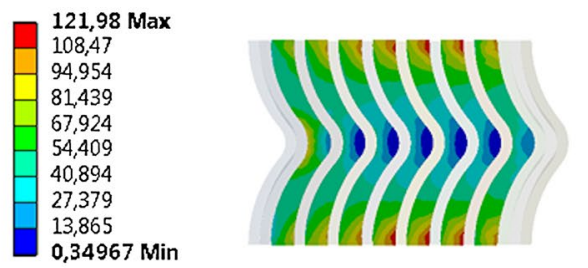

(d) Compression $0.9 \mathrm{~mm}$

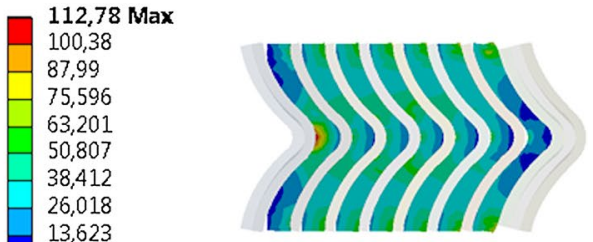


Fig. 16 Numerical results of gasket with tape profile $R_{1}=0.5 \mathrm{~mm} R_{2}=2 \mathrm{~mm}$, a relationship of the max. equivalent stress in elastic tape versus compression of windings, $\mathbf{b}$ course of the contact pressure versus gasket's strain (a)

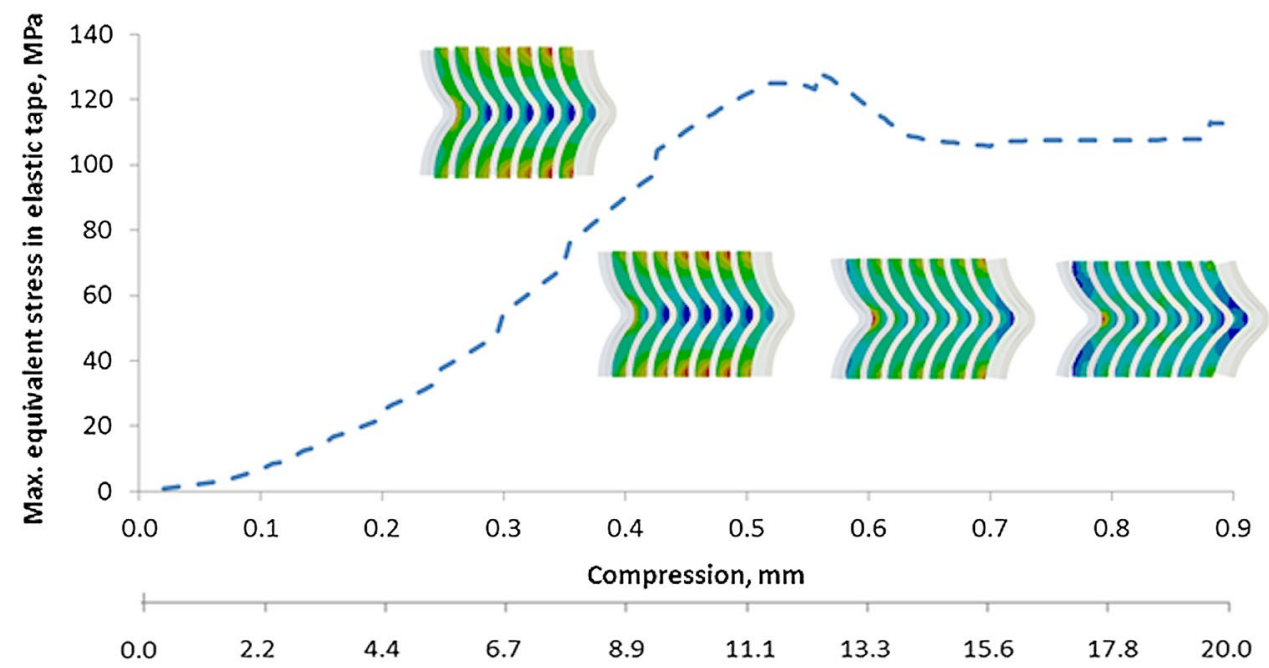

(b)

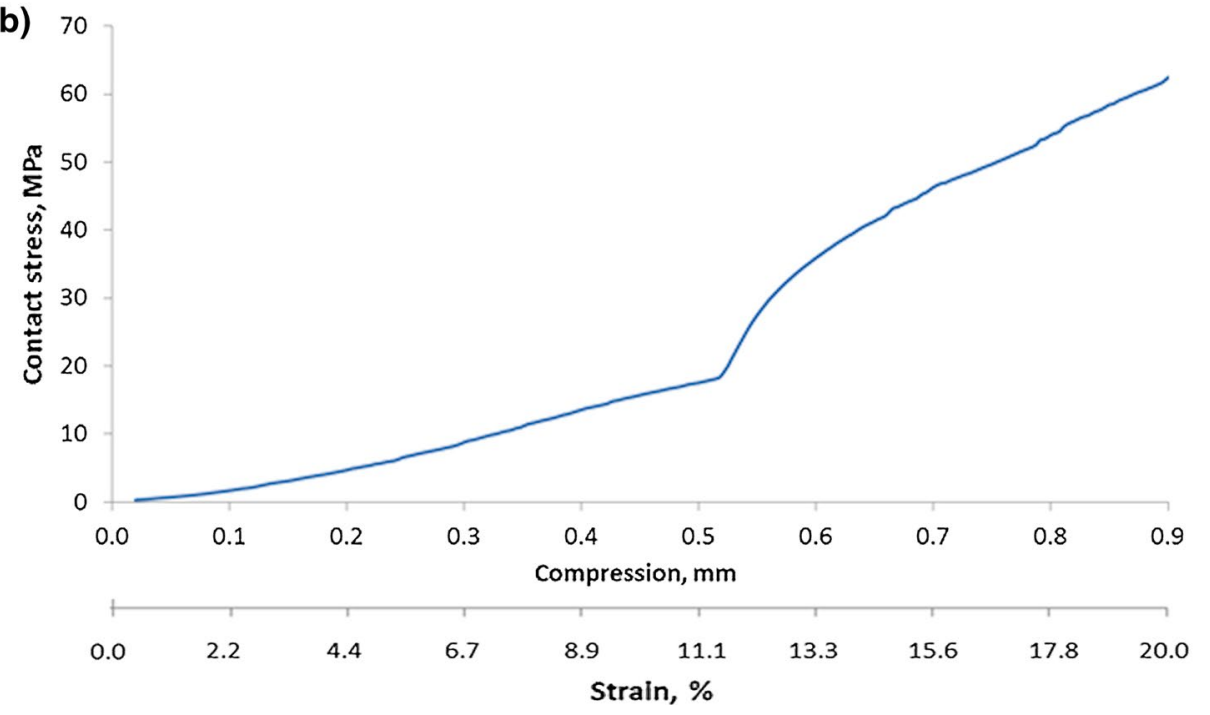

was formulated as static with an active, nonlinear function of the material including a plastic deformation and large displacements. The discrete equation of motion was the same as (8). The upper/lower plates of the hydraulic press and the metal tape of the gasket were modeled with a steel material with Young's modulus $E=200,000 \mathrm{MPa}$ and Poisson ratio $v=0.3$ (typical values of stainless steel). The plastic deformation of the metal tape was approximated by a bilinear plasticity model where the tangent modulus, after exceeding the yield stress $R_{\mathrm{p} 0.2}=200 \mathrm{MPa}$, was $E_{\mathrm{u}}=8000 \mathrm{MPa}$. Equation (6) presented in chapter 3 was used to model CEG's elastic tape. The shear modulus was set as $G=15 \mathrm{MPa}$.

The equation motion (8) was solved by the Newton-Raphson method. The numerical model of the gasket and plates as well as the boundary conditions is presented in Fig. 13. The calculations were divided into two basic steps. First, the initial tension of the gasket was introduced to simulate the effect of its preliminary compression resulting from the winding process. Next, the displacement of the upper plate was incrementally applied $\Delta U_{\mathrm{z}}=0.05 \mathrm{~mm}$ to reach the final value $U_{\mathrm{z}}=0.9 \mathrm{~mm}$. Figure 14 outlines examples of the gasket's profiles depending on the values of $R_{1}$ and $R_{2}$ radii.

\subsection{Computational results}

Figure 15 shows the distribution of the equivalent stress in the elastic tape at selected points of gasket's compression $\left(R_{1}=0.5 \mathrm{~mm}, R_{2}=2.0 \mathrm{~mm}\right)$. In compression up to $0.5 \mathrm{~mm}$, the highest value of the equivalent stress in the elastic tape appeared in the vicinity of sharp edges of the metal tape. In compression ranging from 0.7 to $0.9 \mathrm{~mm}$, the maximum value of the equivalent stress is located in the middle section of the structure and exactly between the first winding of the elastic and metal tapes. The course of the maximum 
Fig. 17 Contact pressure versus gasket strain, tape profile $R_{1}=0.5 \mathrm{~mm} R_{2}=$ var

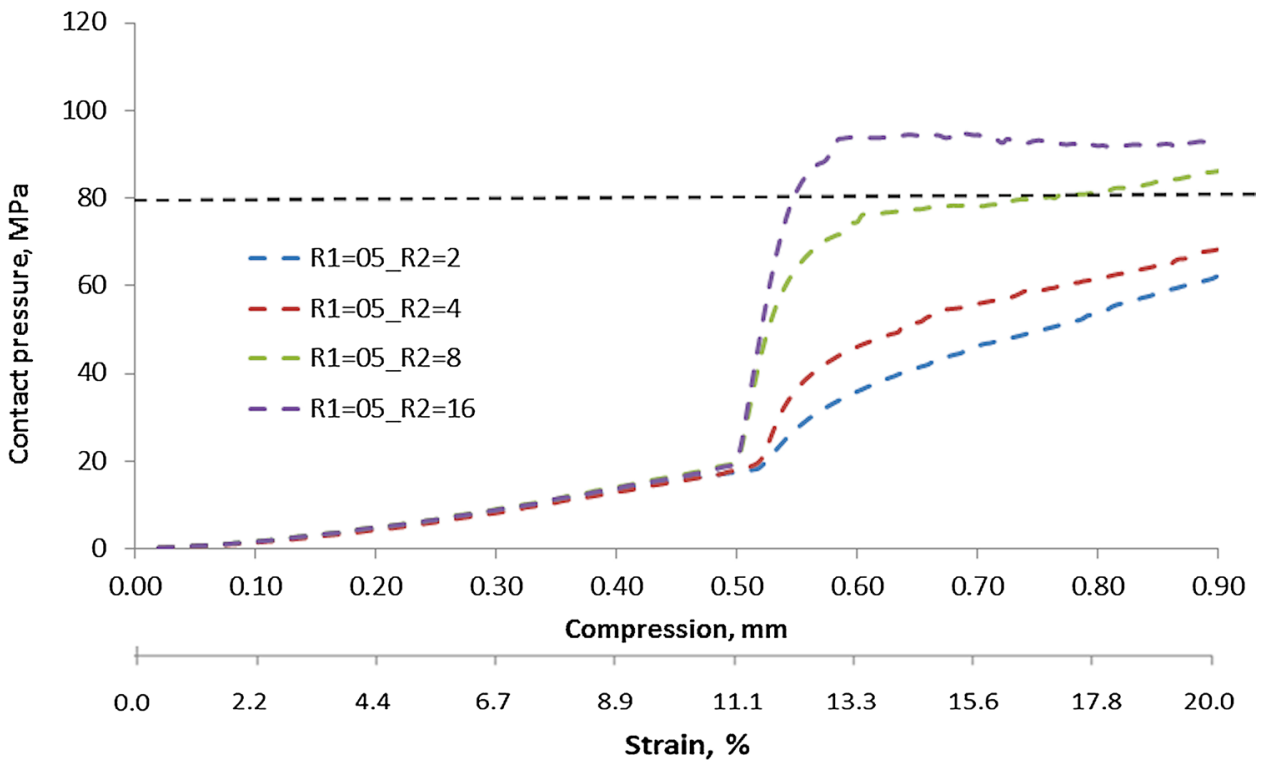

value of the equivalent stress in the elastic tape as a function of the gasket's strain is presented in Fig. 16a. In the initial strain phase, the stress increases in a progressive way. At the compression $U_{\mathrm{z}}=0.5 \mathrm{~mm}$, stress reaches the maximum value, i.e., $\sigma_{\max }=122 \mathrm{MPa}$. After exceeding the compression $U_{\mathrm{z}}>0.5 \mathrm{~mm}$ stress decreased, and finally at $U_{\mathrm{z}}=0.9 \mathrm{~mm}$ stabilized to the value $\sigma_{\max }=113 \mathrm{MPa}$. Figure $16 \mathrm{~b}$ shows the course of the contact pressure as a function of the gasket's compression. The contact pressure was calculated by dividing the reaction force (of the upper plate) by the initial top surface of the gasket. In the chart (Fig. 16b), two characteristic regions can be seen.
The first, ranging from 0 to $0.5 \mathrm{~mm}$, was responsible for the compression of graphite tapes protruding beyond the metal tapes. The second, beginning from $0.5 \mathrm{~mm}$, represented the moment of contact of the metal tapes with metal plates. From that point, the increment of the contact pressure strongly increased up to $0.7 \mathrm{~mm}$.

When compression exceeded $0.7 \mathrm{~mm}$, the contact stress increased linearly up to $0.9 \mathrm{~mm}$. In the whole range of compression, the course of the function $p=f(\varepsilon)$ is progressive. Nevertheless, the tape profile in this configuration did not meet the constraint (15), because $20 \%$ of strain occurred at the contact pressure of $65 \mathrm{MPa}$. Figure 17 presents a set of contact pressure versus gasket's strain for the profile tape
Fig. 18 Max. equivalent stress in elastic tape versus gasket's strain, tape profile $R_{1}=0.5 \mathrm{~mm}$ $R_{2}=$ var

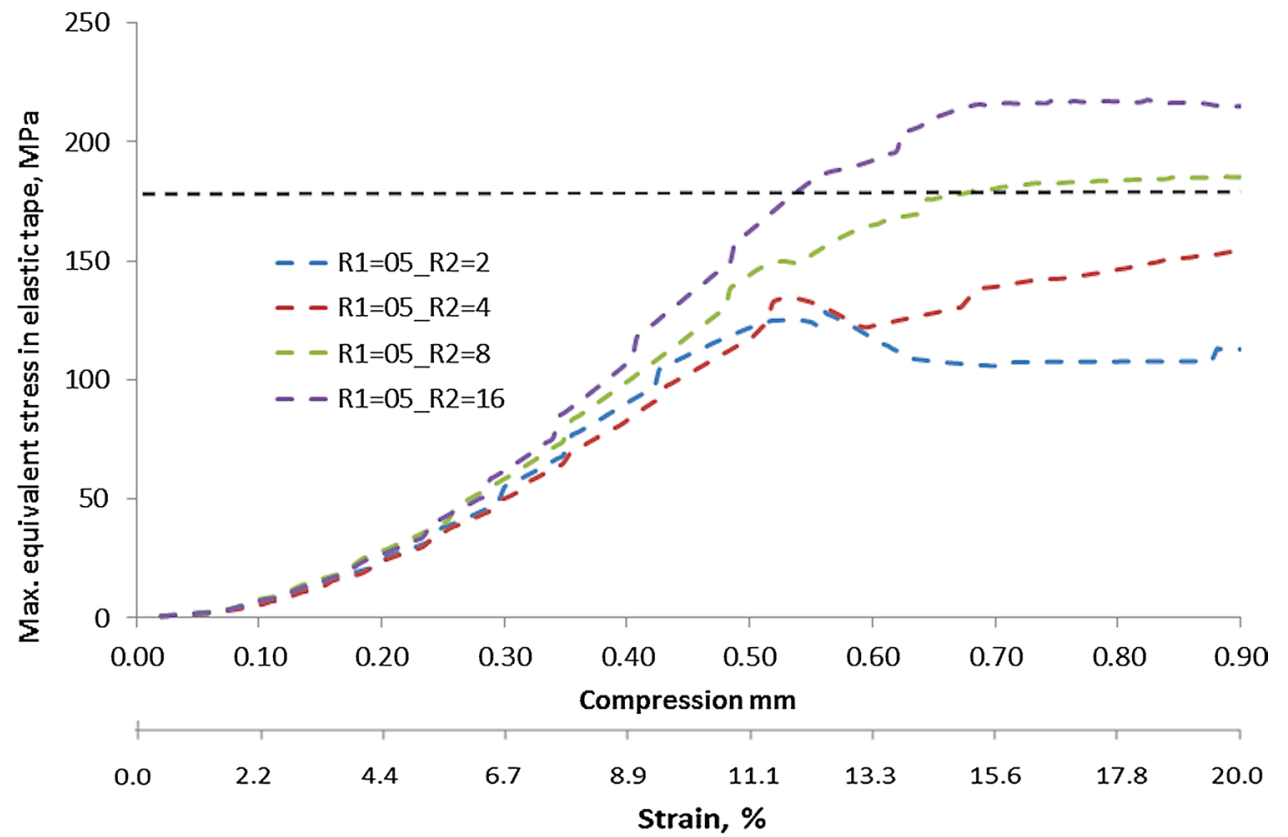


$R_{1}=0.5 \mathrm{~mm}$ and variable values of radius $R_{2}$. Taking into account the imposed constraints, only the metal tape variant of $R_{2}=8 \mathrm{~mm}$ and $R_{2}=16 \mathrm{~mm}$ meets the requirement (15). However, both configurations exceed the constraint (16), since the maximum equivalent stress in the elastic tape is greater than $180 \mathrm{MPa}$ (Fig. 18).

Furthermore, characteristic $p=f(\varepsilon)$ of the variant $R_{2}=16 \mathrm{~mm}$ in the compression range from 0.6 to $0.9 \mathrm{~mm}$ behaves unstably; hence, it exceeds the constraint (17). An interesting course of the characteristic $p=f(\varepsilon)$ was observed in the variant of the tape profile $R_{1}=2 \mathrm{~mm}$ and a variable radius $R_{2}$ (Fig. 19).

Except for the variants $R_{2}=2 \mathrm{~mm}$ and $R_{2}=4 \mathrm{~mm}$, other profile configurations met the constraint (15). Nonetheless, each of them exceeded the constraint (16) $\sigma_{\max }>180 \mathrm{MPa}-$ Fig. 20. In case of the profile tape $R_{1}=4 \mathrm{~mm} R_{2}=$ var, all solutions fulfill the constraint (15) (Fig. 21), whereas only two configurations $R_{2}=4 \mathrm{~mm}$ and $R_{2}=8 \mathrm{~mm}$ do not exceed the constraint (16) (Fig. 21) and the constraint (17) (Fig. 22); therefore, they meet all requirements.
Fig. 19 Contact pressure versus strain, tape profile $R_{1}=2 \mathrm{~mm}$ $R_{2}=$ var

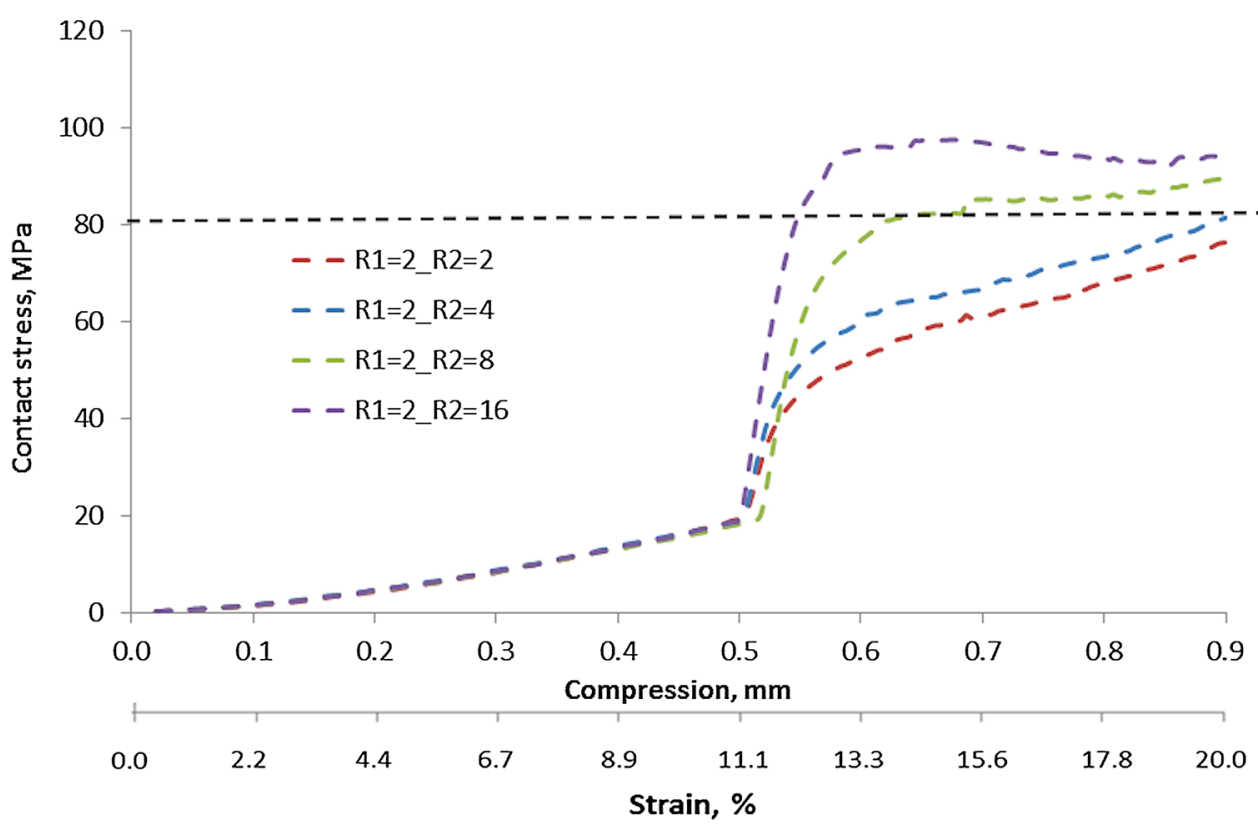

Fig. 20 Max. equivalent stress in elastic tape versus gasket's strain, tape profile $R_{1}=2 \mathrm{~mm}$ $R_{2}=$ var

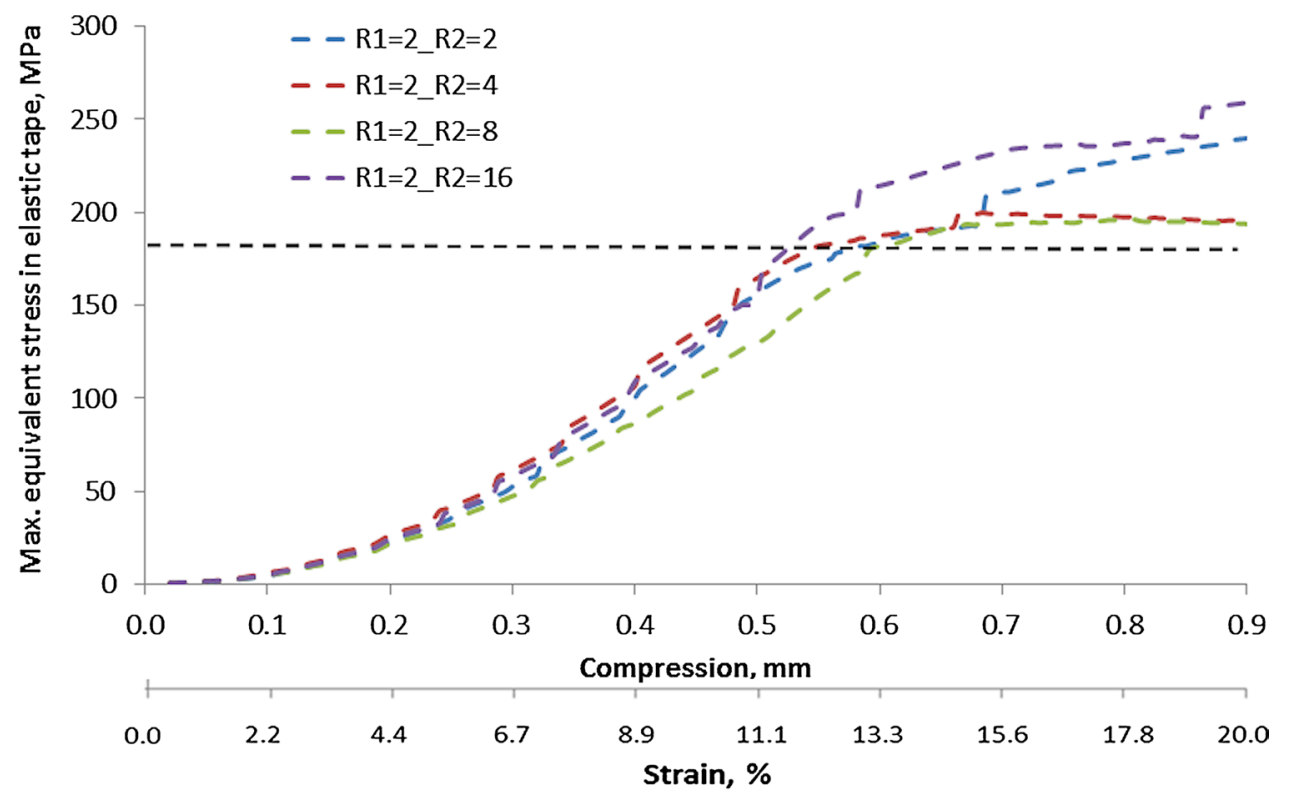


Fig. 21 Contact pressure versus gasket's strain, tape profile $R_{1}=4 \mathrm{~mm} R_{2}=$ var

Fig. 22 Max. equivalent stress in elastic tape versus gasket's strain, tape profile $R_{1}=4 \mathrm{~mm}$ $R_{2}=\mathrm{var}$
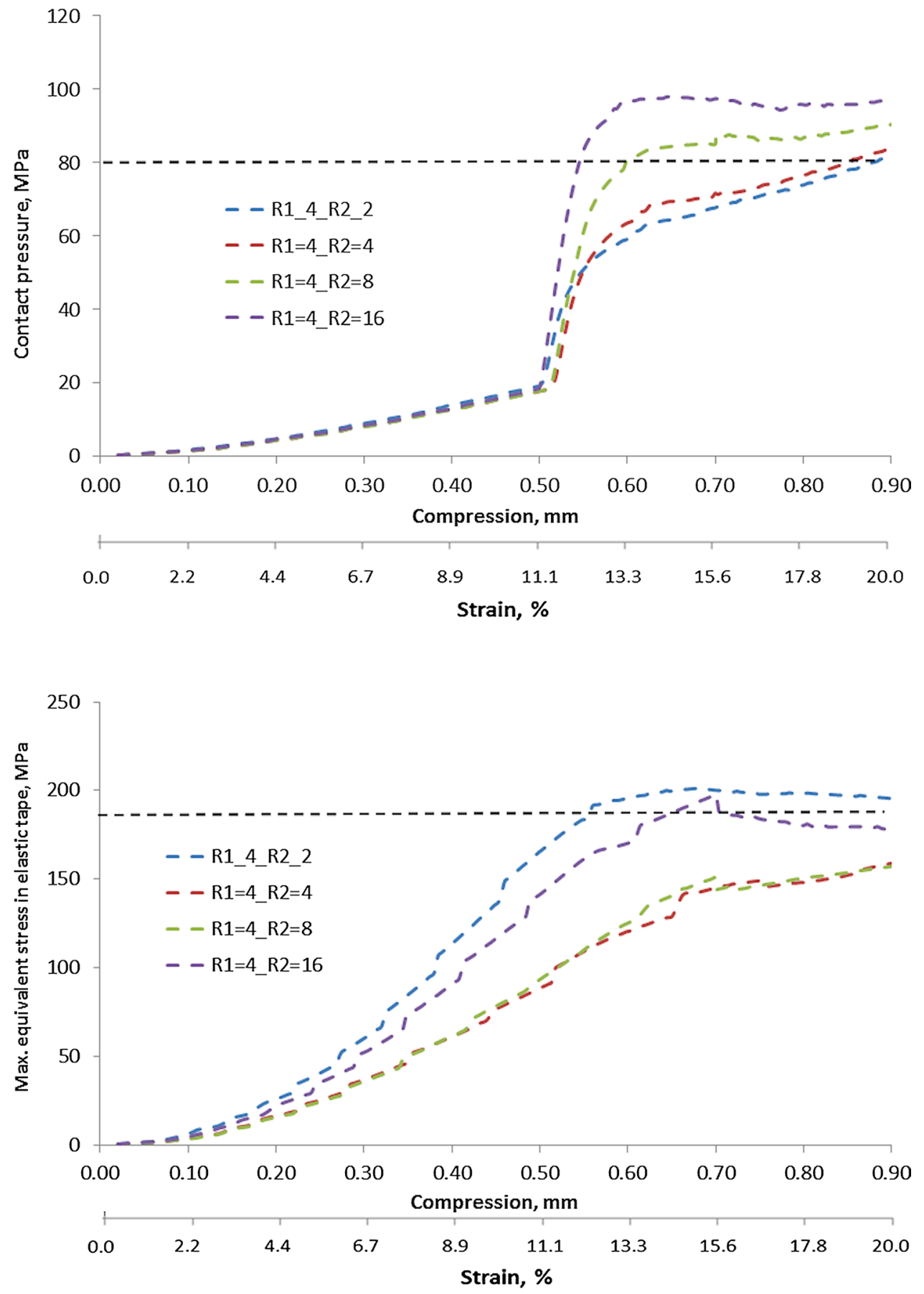

Figure 23 shows a course of the contact pressure as a function of the gasket's strain for tape parameters $R_{1}=8 \mathrm{~mm}$, $R_{2}=$ var. All configurations met the constraint (15). However, the courses of functions $p=f(\varepsilon)$ of variants $R_{2}=8 \mathrm{~mm}$ and $R_{2}=16 \mathrm{~mm}$ were out of the constraint (17). Moreover, each of the variants of the tape's profile exceeded the constraint (16) $\sigma>180 \mathrm{MPa}$ (Fig. 24). Similar relations were obtained in case of the tape profile $R_{1}=16 \mathrm{~mm}, R_{2}=$ var.

At the deformation $0.9 \mathrm{~mm}$, characteristics describing the dependence of the contact pressure versus gasket's strain practically met in one point (Fig. 25) and fulfill the limitation (15) but they exceed the limitation (17). 
Fig. 23 Contact pressure versus windings strain, tape profile $R_{1}=8 \mathrm{~mm} R_{2}=$ var
Fig. 24 Max. equivalent stress in elastic tape versus gasket's strain, tape profile $R_{1}=8 \mathrm{~mm}$ $R_{2}=$ var
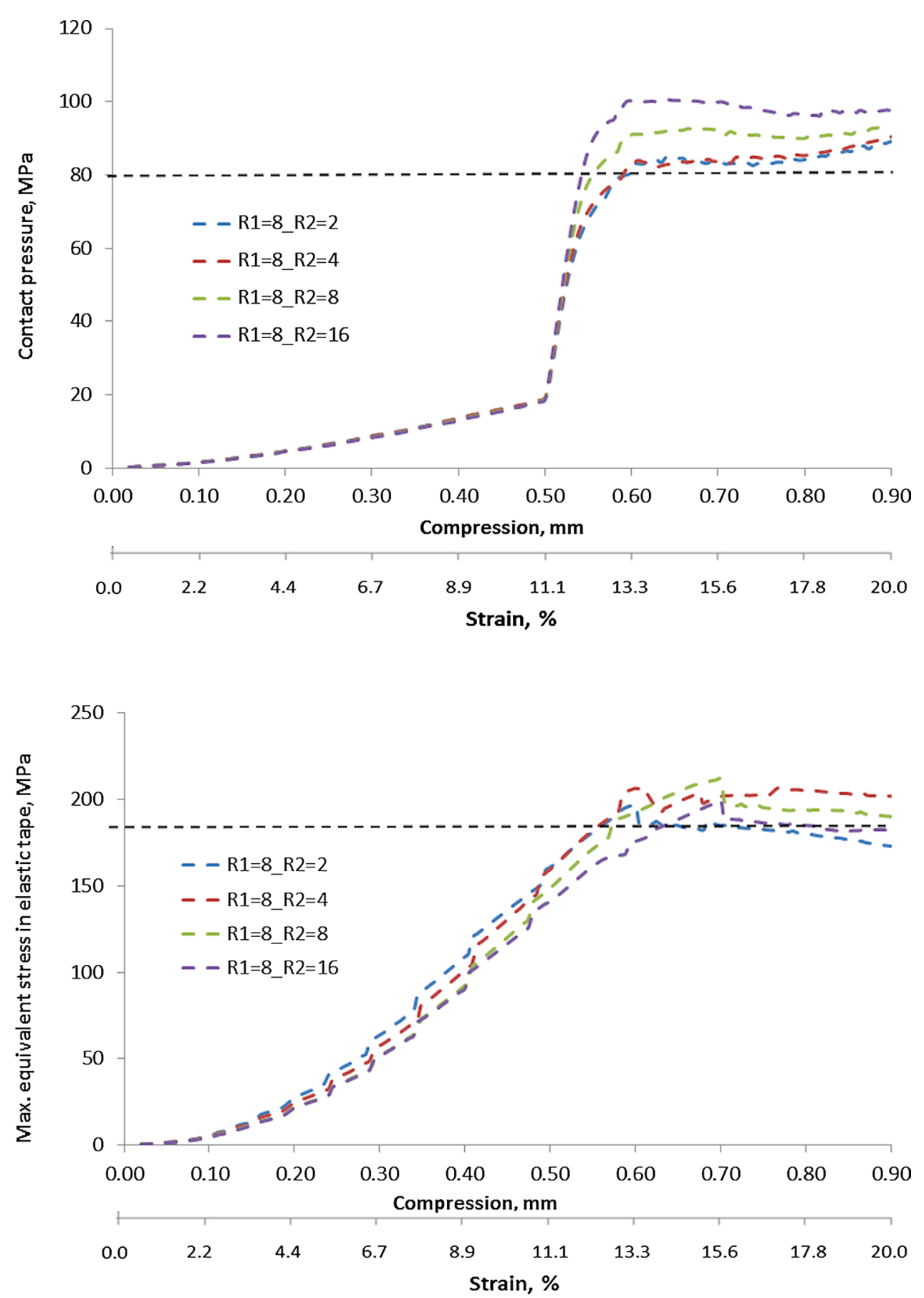

Furthermore, each variant exceeded the constraint (16) see Fig. 26. Figure 27a shows a contour plot of the maximum equivalent stress in the elastic tape as a function of parameters $R_{1}$ and $R_{2}$. It can be seen that the four variants fulfill the constraint (16). In Fig. 27b the contour plot of contact stress at $20 \%$ of gasket's strain versus radii $R_{1}$ and $R_{2}$ is presented.
Only three variants of the tape profile: $\left(R_{1}=4 \mathrm{~mm}\right.$, $\left.R_{2}=4 \mathrm{~mm}\right),\left(R_{1}=2, R_{2}=4 \mathrm{~mm}\right)$ and $\left(R_{1}=2 \mathrm{~mm}, R_{2}=8 \mathrm{~mm}\right)$ fulfilled the constraint (15). Solutions fulfilling the limitations (15), (16) and (17) are collected in Fig. 27c. It can be noticed that only one profile configuration $\left(R_{1}=4 \mathrm{~mm}\right.$, $R_{2}=4 \mathrm{~mm}$ ) covers both requirements. 
Fig. 25 Contact pressure versus gasket's strain, tape profile $R_{1}=16 \mathrm{~mm} R_{2}=$ var

Fig. 26 Max. equivalent stress in elastic tape versus gasket's strain, tape profile $R_{1}=16 \mathrm{~mm}$ $R_{2}=$ var
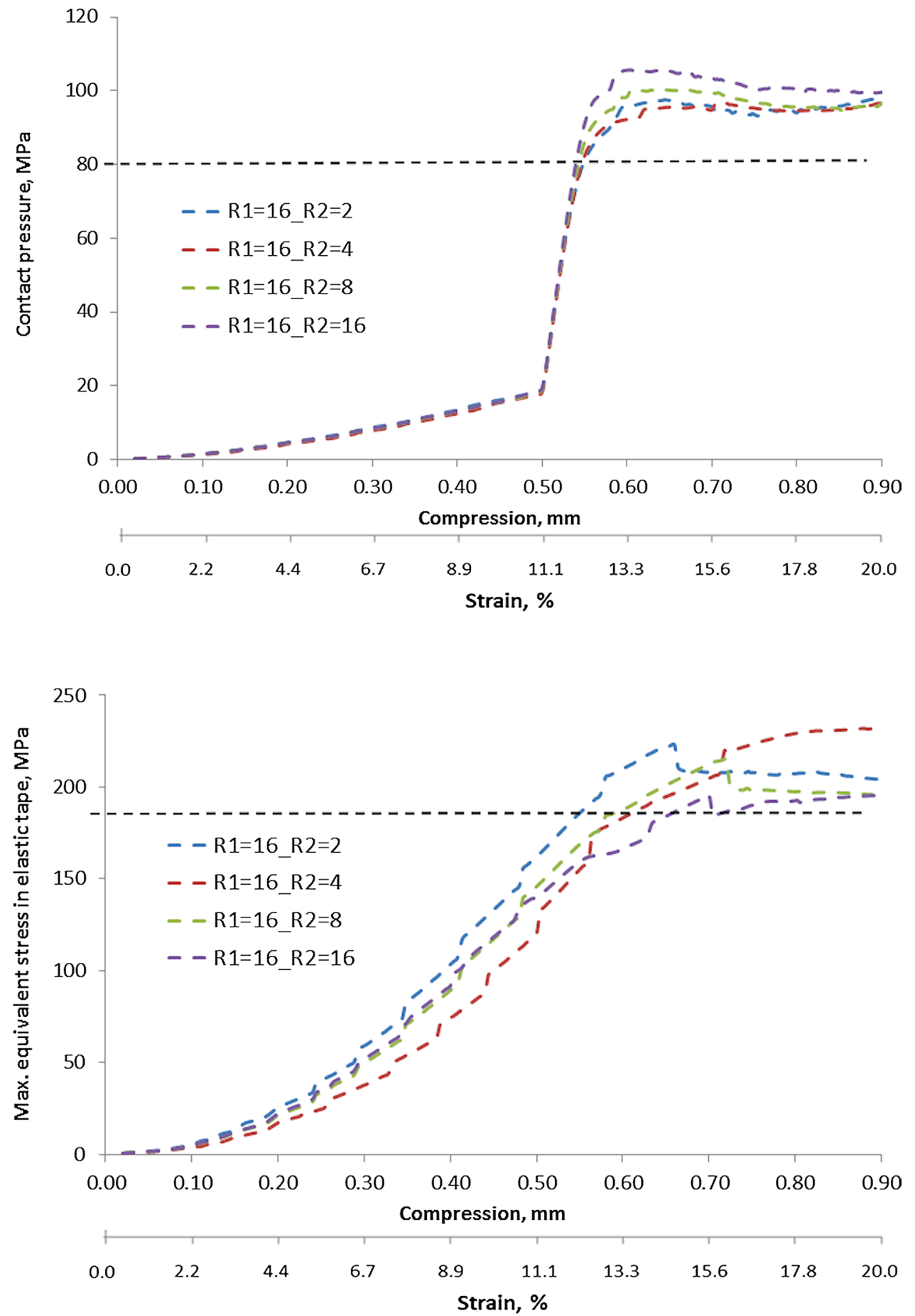

Figure 28 presents maps of the maximum stress distribution at the characteristic points of compression of the gasket's optimal variant $R_{1}=4 \mathrm{~mm}$ and $R_{2}=4 \mathrm{~mm}$. Figure 29 presents a separate graph of the characteristics describing dependence of the contact pressure and the maximum stress in the elastic tape as a function of strain. The tape profile $R_{1}=4 \mathrm{~mm}$ and $R_{2}=4 \mathrm{~mm}$ was finally made and tested experimentally. 
Fig. 27 A collection of numerical results at different gasket's variants, a counter plot of maximum equivalent stress in graphite tape, b counter plot of contact stress acting on the gasket's top surface at its strain $20 \%$, c collection of tape variants which fulfills all constraints (a)

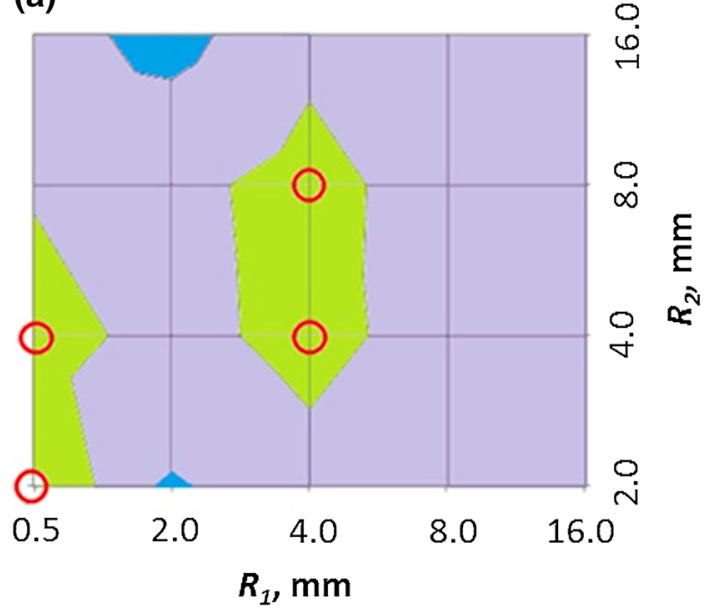

(b)

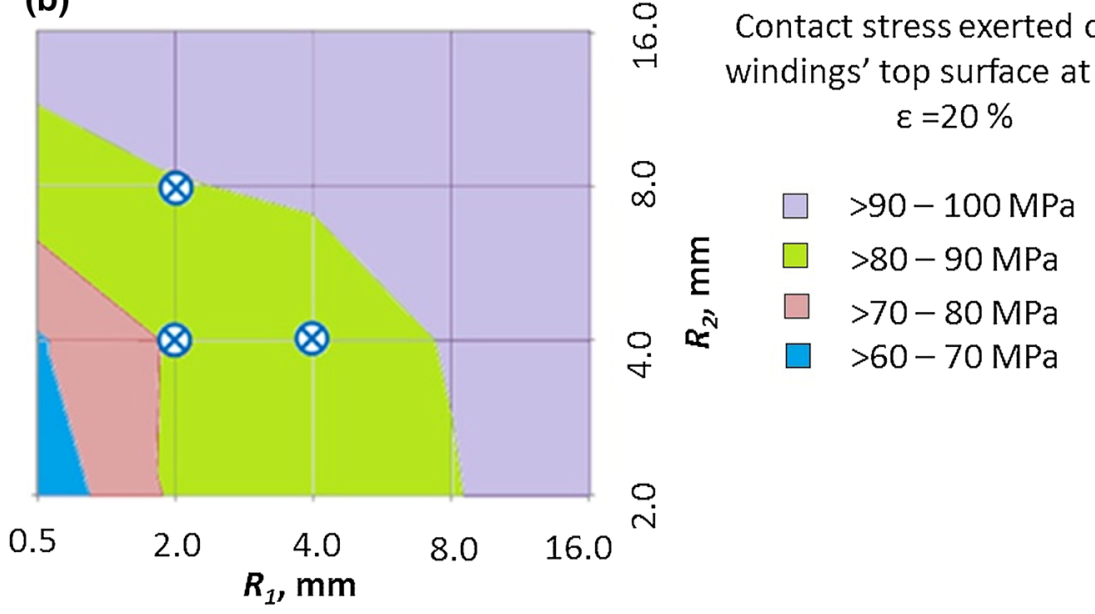

(c)

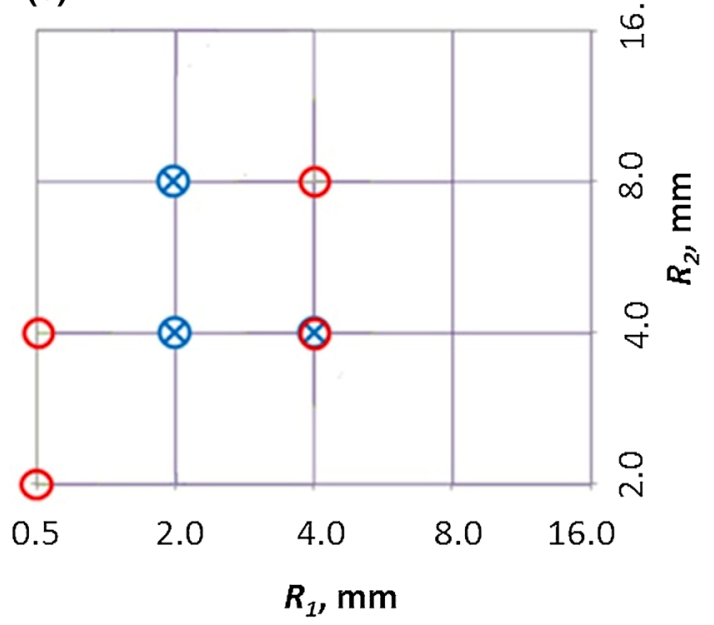

$\bigcirc$ Variants meet limitation $g(s)=\sigma_{\max } \leq \sigma_{\text {permis } .}=180 \mathrm{MPa}$

(8) Variants meet limitation $p(s)>80$ at $\varepsilon=20 \%$

( Variants meet all limitation 
Fig. 28 Distribution of equivalent stress (MPa) in graphite tape in subsequent deformation steps for profile variants $R_{1}=4.0 \mathrm{~mm}$ and $R_{2}=4.0 \mathrm{~mm}$; a compression $0.3 \mathrm{~mm}$, b compression $0.5 \mathrm{~mm}$, c compression $0.7 \mathrm{~mm}, \mathbf{d}$ compression $0.9 \mathrm{~mm}$ (a) Compression $0.3 \mathrm{~mm}$

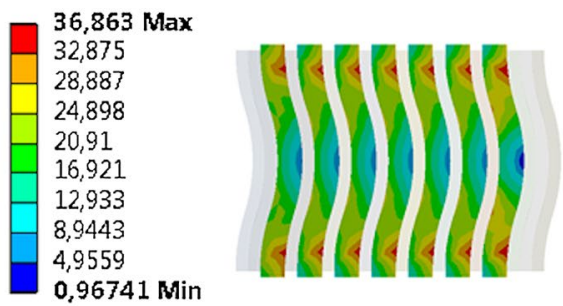

(c) Compression $0.7 \mathrm{~mm}$

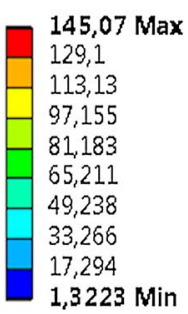

(b) Compression $0.5 \mathrm{~mm}$

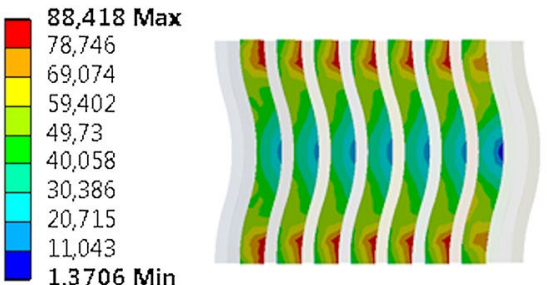

(d) Compression $0.9 \mathrm{~mm}$

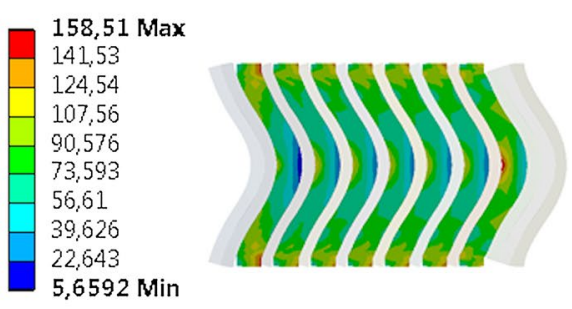

\subsection{Optimized SWG}

In order to verify the numerical gasket's model, the optimized variant was subjected to an experimental test. The experiment was conducted on the same test rig as presented in Fig. 6. The gasket located on the lower plate of a hydraulic press before the compression test is presented in Fig. 30. The sample was compressed up to a maximum value $0.9 \mathrm{~mm}$. The experimental results in the form of the contact pressure versus gasket's compression against the numerical results are compiled in Fig. 31. In the initial phase of compression from 0 to $0.5 \mathrm{~mm}$, both curves were practically overlapping. In the compression region where the metal tape comes into contact with the press plates (from 0.5 to $0.6 \mathrm{~mm}$ ), some differences between both compression curves were observed.

At strain of $20 \%$ the contact pressure exerted on the gasket's top surface was $87 \mathrm{MPa}$ (in a numerical result it was $82 \mathrm{MPa}$ ). In the whole range of deformations, the compression curve is progressive.

\section{Summary}

The hyperelastic B-K model is mainly dedicated to model elastic strain energy of highly compressible elastomers which are characterized by cellular open foam. To this group of materials belongs, among others, PUF. In view of similar physical properties of CEG to PUF, the B-K model, at some assumptions, is compatible with a real deformation of CEG subjected to the compressive load. Those assumptions resulted mainly from treating CEG as an isotropic material, not plastically deformable, which in real behavior of CEG is not met. The only parameter in the B-K model depending on properties of the material was the shear modulus referring to the initial state of infinitesimal strain. In case of CEG with bulk density of $0.8 \mathrm{~g} / \mathrm{cm}^{3}$ (experimentally verified), the best mapping of a real compressive curve was obtained at the shear modulus $G=15 \mathrm{MPa}$. The material model verified in this way was used for optimization of the spiral wound gasket. The aim of the optimization was to minimize the stress in the elastic tape and provide an adequate axial gasket's stiffness through shaping the gasket's cross section (consisting of metal and elastic tapes). The radii $R_{1}$ and $R_{2}$ describing the profile of the metal tape were assumed to be variable parameters. Twenty variants of the gasket's configurations were taken into consideration. It was shown that there is a set of parameters $\left(R_{1}, R_{2}\right)$ which met the set requirements. Generally, the increase of radius $R_{1}$ leads to the increase in the gasket's stiffness, while the decrease in radius $R_{2}$ causes higher tension in the elastic tape. The optimal solution was found in the form of $R_{1}=4 \mathrm{~mm}, R_{2}=4 \mathrm{~mm}$. The optimized shape of the gasket was verified by experimental tests. 
Fig. 29 Numerical results of gasket's tape profile $R_{1}=4.0 \mathrm{~mm} R_{2}=4.0 \mathrm{~mm}, \mathbf{a}$ relationship of the max. equivalent stress in elastic tape versus gasket's compression, $\mathbf{b}$ course of the contact pressure versus gasket's strain (a)

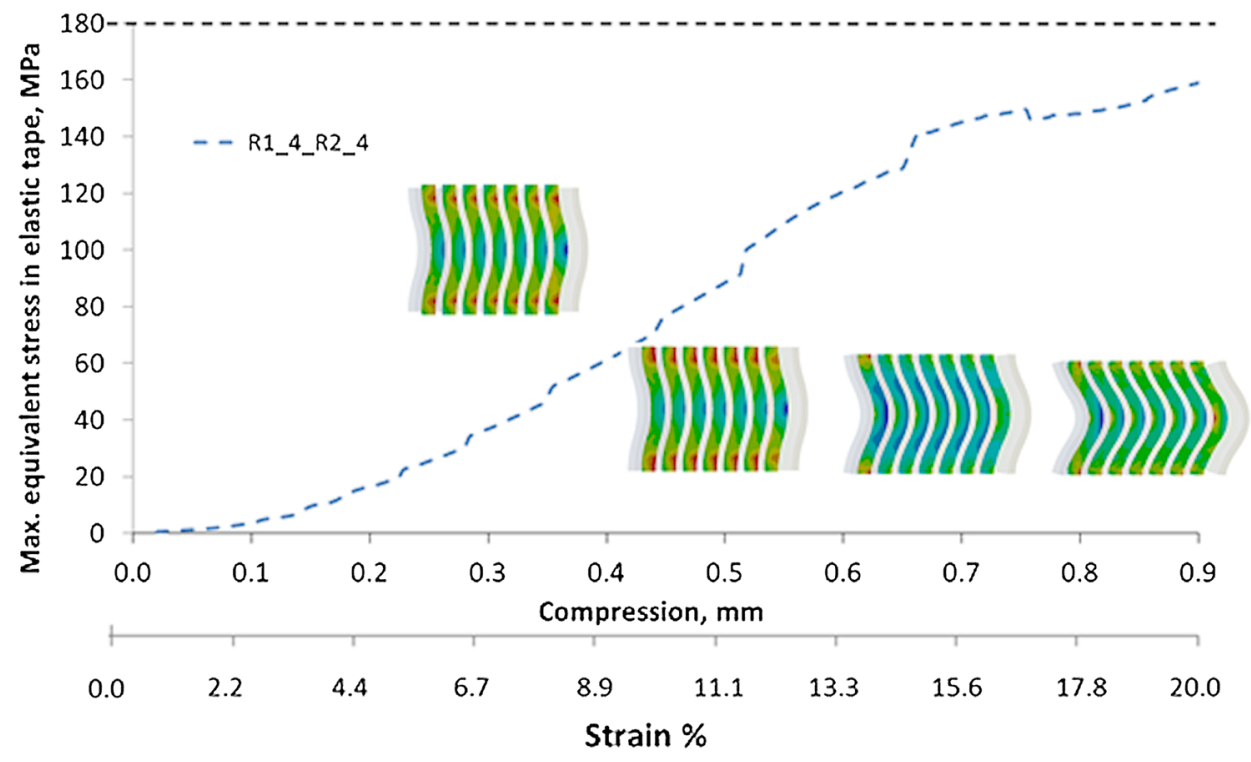

(b)

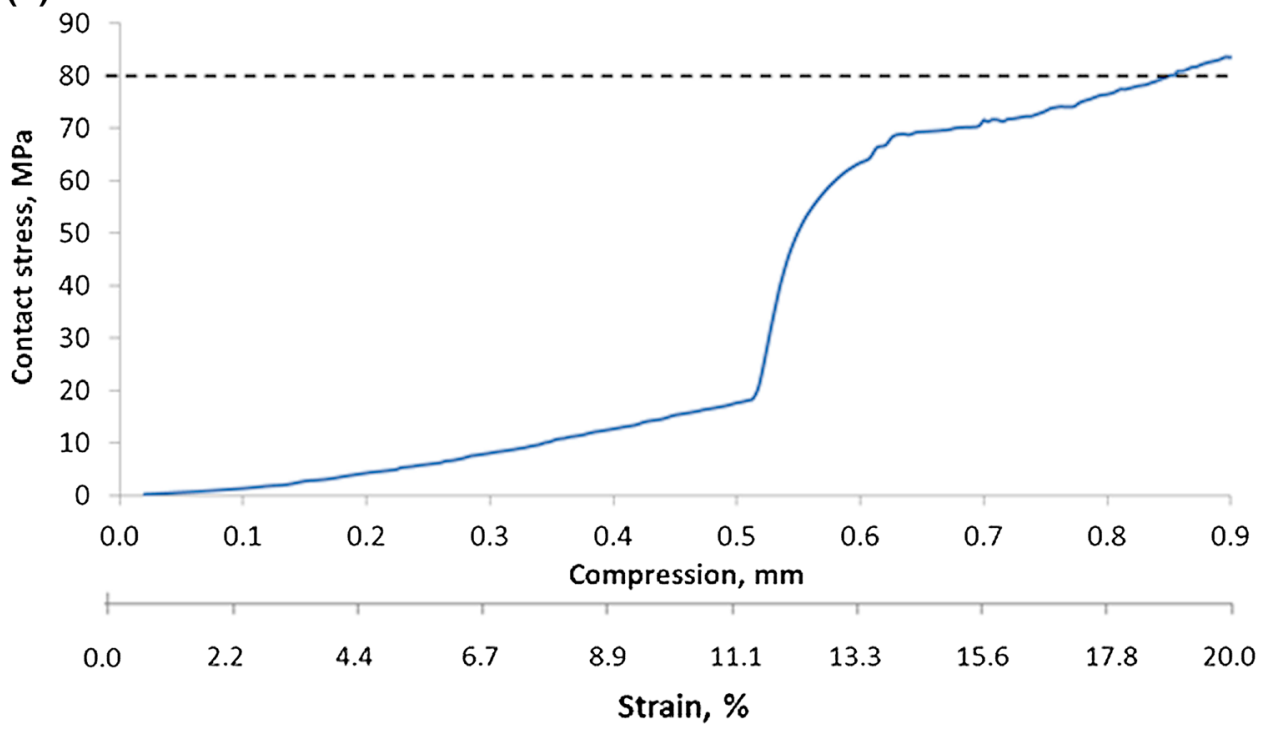

Slight discrepancies between numerical and experimental outcomes resulted mainly from the assumed simplifications, such as treating CEG as an isotropic and fully elastic material, with no ability to dissipate energy through an internal friction as well as assuming that the friction coefficient on the cooperating surface steel-CEG equals 0.4.

\section{Main conclusions of the work}

- Assuming that CEG is an isotropic and hyperelastic material, the B-K model can be used to map, with high accuracy, the deformation of CEG under axial compression. 


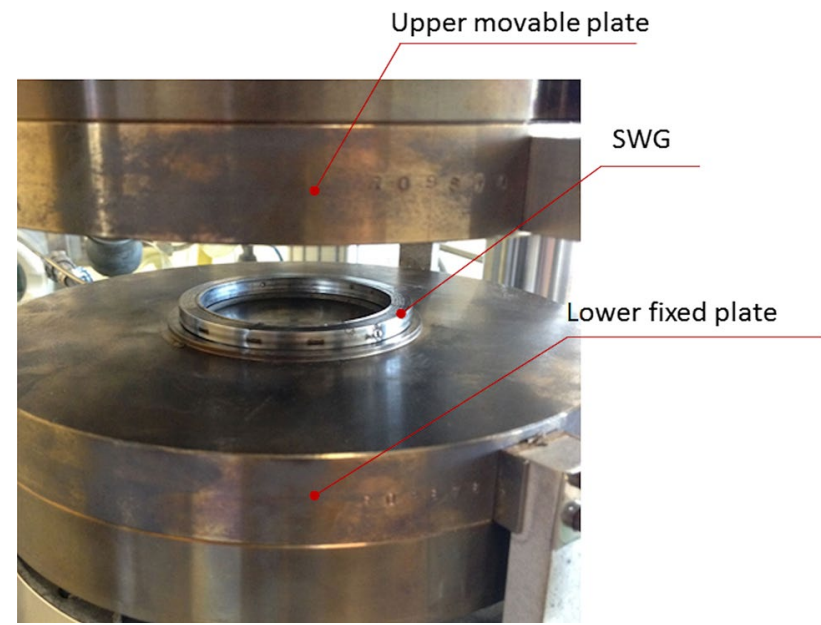

Fig. 30 Optimized windings situated on lower plate of test rig before the compression test
- A value of the material constant of the B-K model in the simulation of CEG strongly depends on the initial value of density/porosity. For modeling CEG with density of about $0.8 \mathrm{~g} / \mathrm{cm}^{3}$, good mapping of the real compression curve was obtained at the shear modulus $G=15 \mathrm{MPa}$.

- Modeling CEG with different density requires an experimental test to determine the correct $G$ value.

- The material model B-K, verified by the experimental research, provides good mapping of the deformation of the spiral wound gasket subjected to a compression load.

- On the basis of the optimization of the spiral wound gasket, it was found that the minimal stress in the elastic tape can be achieved by adapting an appropriate shape of the cross section profile of the metal tape.

- Decreasing radius $R_{2}$ of the metal tape leads to excessive tension of the elastic tape, while the increasing radius $R_{1}$ of the metal tape causes the increase in the axial stiffness of the gasket.
Fig. 31 Verification of numerical model of winding with optimized shape

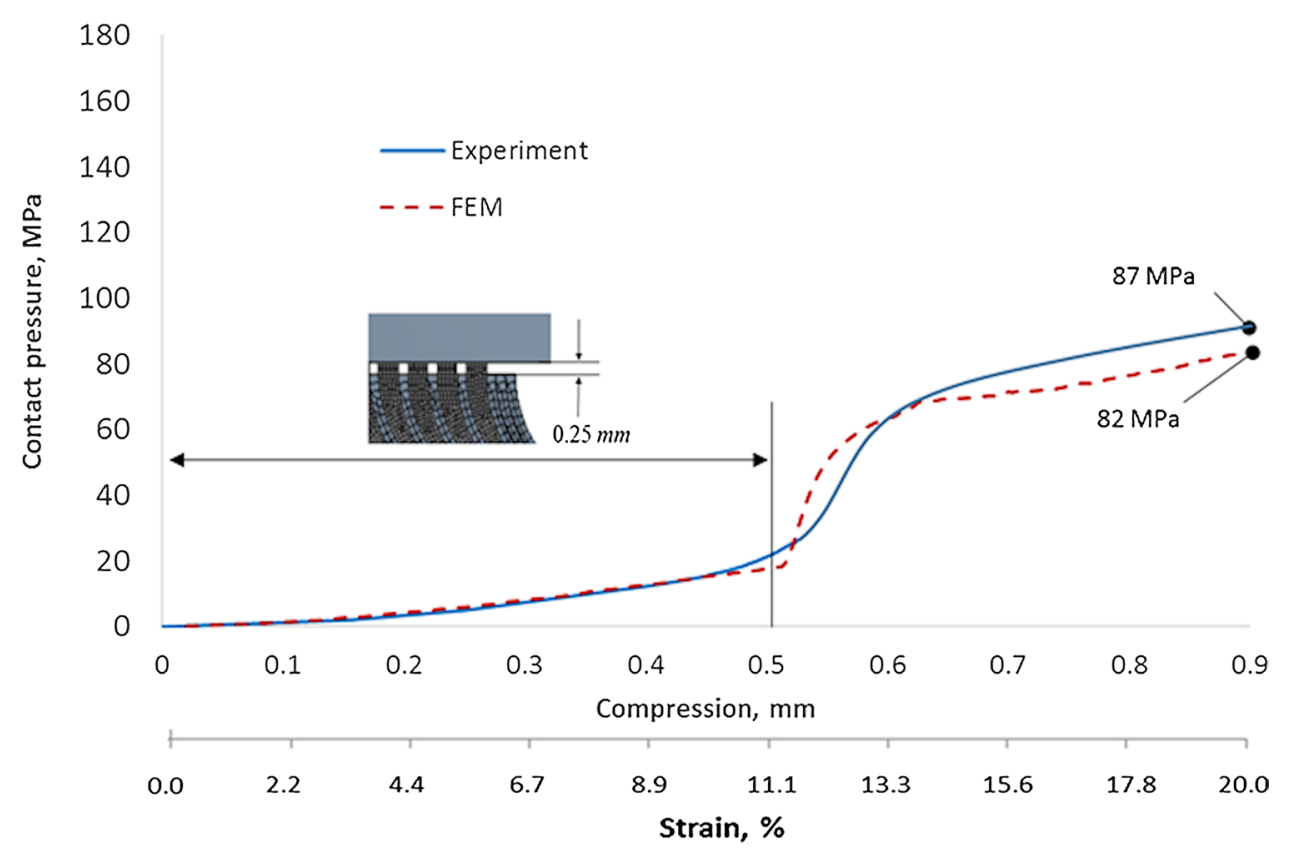


Acknowledgements Calculations have been carried out using resources provided by Wroclaw Centre for Networking and Supercomputing (http://wcss.pl), Grant No. 444.

Open Access This article is licensed under a Creative Commons Attribution 4.0 International License, which permits use, sharing, adaptation, distribution and reproduction in any medium or format, as long as you give appropriate credit to the original author(s) and the source, provide a link to the Creative Commons licence, and indicate if changes were made. The images or other third party material in this article are included in the article's Creative Commons licence, unless indicated otherwise in a credit line to the material. If material is not included in the article's Creative Commons licence and your intended use is not permitted by statutory regulation or exceeds the permitted use, you will need to obtain permission directly from the copyright holder. To view a copy of this licence, visit http://creativecommons.org/licenses/by/4.0/.

\section{References}

1. Shane H, Russel RJ, Bochman RA (1968) US Patent 3,404,061

2. Mortazavi B, Hassouna F, Laachachi A, Rajabpour A, Ahazi S, Chapron C, Toniazzo V, Ruch D (2013) Experimental and multiscale modeling of thermal conductivity and elastic properties of PLA/expanded graphite polymer nano-composites. Thermochim Acta 552:106-113

3. Gama N, Costa LC, Amaral V, Ferreira A, Barros-Timmons A (2017) Insights into the physical properties of biobased polyurethane/expanded graphite composite foams. Compos Sci Technol 138:24-31

4. Cho J, Luo JJ, Daniel IM (2007) Mechanical characterization of graphite/epoxy nanocomposites by multi-scale analysis. Compos Sci Technol 67:2399-2407

5. Kim IH, Jeong YG (2010) Polylactide/exfoliated graphite nanocomposites with enhanced thermal stability, mechanical modulus, and electrical conductivity. J Polym Sci Part B 48(8):850-858

6. Kim LJ, Sham JM (2005) Conductive graphite nanoplatelet/epoxy nanocomposites: effects of exfoliation and UV/ozone treatment of graphite. Scripta Mater 53:235-240

7. Guler T, Tayfun U, Bayramli E, Dogan M (2017) Effect of expandable graphite on flame retardant, thermal and mechanical properties of thermoplastic polyurethane composites filled. Thermochim Acta 647:70-80

8. Fanasov IM, Savchenko DV, Ionov SG, Rusakov DA, Seleznev AN, Avdeev VV (2009) Thermal conductivity and mechanical properties of expanded graphite. Inorg Mater 45(5):486-490

9. Vovchenko LL, Matzui LYu, Kulichenko AA (2007) Thermal characterization of expanded graphite and its composites. Inorg Mater 43(43):597-601

10. Krzesinska M, Pisaroni N (2004) Mechanical properties of monolithic compressed expanded graphite-based adsorbents related to the temperature of pyrolysis and activation, studied with ultrasound. Mater Charact 52:195-202

11. Celzard A, Mareche JF, Furdin G (2003) Describing the properties of compressed expanded graphite through power laws. J Phys Condens Matter 15:7213-7226

12. Dowell MB, Howard R (1986) Tensile and compressive properties of flexible graphite foil. Carbon 24:311-323

13. Chung DDL (2000) Flexible graphite for gasketing, adsorption, electromagnetic interference shielding, vibration damping, electrochemical applications, and stress sensing. J Mater Eng Perform 9(2):161-163

14. Sorokina NE, Redchitz AV, Ionov SG, Avdeev VV (2006) Different exfoliated graphite as a base of sealing materials. J Phys Chem Solids 67:1202-1204

15. Veiga JC, Monteiro da Silva G, Kavanagh N (2013) Factors that influence the sealing behavior of spiral wound gasket. In: Proceedings of the ASME 2013 pressure vessel and piping division conference PVP2013 July 14-18, 2013, Paris, France

16. Mc Carthy J, Fitzgerald A, Reid D (2013) Spiral wound gasket compressibility and pressure ratings. In: Proceedings of the ASME 2013 pressure vessels and piping conference PVP2013, July $14-18$, Paris, France

17. Waterland AH (2009) Analysis of the compression behavior of spiral wound gasket. In: Proceedings of the 2009 ASME pressure vessels and piping division conference July 26-30 Prague, Czech Republic, Paper No. PVP, pp 89-97

18. Veiga JC, Cipolatti CF, Kavanagh N, Reeves D (2011) The influence of winding density in the sealing behavior of spiral wound gaskets. In: Pressure vessels and piping conference ASME, Jan 2011, pp 103-111

19. Meyer R, Kolb SK Low stress/anti-buckling spiral wound gasket. International application published under the patent cooperation treaty, WO 2017/087643 A2

20. Attoui H, Bouzid AH, Waterland JA (2014) Buckling and lateral pressure in spiral wound gaskets. Proceedings of the ASME 20. In: Pressure vessel and piping conference 2014, Volume 2: computer technology and bolted joints, Anaheim, California, USA, July 20-24, pp 1-7

21. Winter JR, Leon GF (1985) Radially inward buckling of spiral wound gaskets. Am Soc Mech Eng Pressure Vessels Piping Div PVP-Vol 98:111-116

22. Larson RA, Bibel G (2005) Experimental and analytical evaluation of buckling forces of a spiral wound flexible gasket. In: Proceedings of the ASME pressure vessels and piping conference-computer technology, PVP-vol 2, pp 97-104

23. Mueller RT (1996) Recent buckling experiences with spiral wound flexible graphite filled gaskets. American society of mechanical engineers, pressure vessels and piping division PVP-Vol. 326, computer technology-applications and methodology, pp 23-34

24. Wang J, He QZ, Pei YY, Shi Y (2014) Effect of angle of v-type steel belt on performance of spiral wound gasket. Appl Mech Mater Adv Civil Struct Eng III 501-504:717-721

25. Fukuoka T, Takaki T (2003) Finite element simulation of bolt-up process of pipe flange connections with spiral wound gasket. J Pressure Vessel Technol 125(4):371-378

26. Abid M, Hussain S (2008) Bolt preload scatter and relaxation behaviour during tightening a 4 in-900 class flange joint with spiral wound gasket. ARCHIVE Proc Inst Mech Eng Part E J Process Mech Eng 222(2):123-134

27. Mathan G, Siva Prasad N (2010) Evaluation of effective material properties of spiral wound gasket through homogenization. Int $\mathrm{J}$ Press Vessels Pip 87:704-713

28. Celzard A, Mareche JF, Furdin G (2005) Modelling of exfoliated graphite. Prog Mater Sci 50:93-179

29. Briody C, Duignan B, Jerrams S (2011) Characterization, modelling and simulation of flexible polyurethane foam. In: International conference on materials. Tribology and recycling (MATRIB). Vela Luka, Croatia, 29 June-01 July, pp 23-36

30. Mane JV, Chandra S, Sharma S, Ali H, Chavan VM, Manjunath BS, Patel RJ (2017) Mechanical property evaluation of 
polyurethane foam under quasi-static and dynamic strain ratesexperimental study. Proc Eng 173:726-731

31. Yonezu A, Hirayama K, Kishida H, Chen X (2016) Characterization of the compressive deformation behavior with strain rate effect of low-density polymeric foams. Polym Test 50:1-8

32. Ouellet S, Cronin D, Worswick M (2006) Compressive response of polymeric foams under quasi-static, medium and high strain rate conditions. Polym Test 25:731-743

33. Fushima S, Nagakura T, Yonezu A (2017) Experimental and numerical investigations of the anisotropic deformation behavior of low-density polymeric foams. Polym Test 63:605-613

34. Tu ZH, Shim VPW, Lim CT (2001) Plastic deformation modes in rigid polyurethane foams under static loading. Int J Solid Struct 38:9267-9279

35. Chen P, Chung DDL (2015) Elastomeric behavior of exfoliated graphite, as shown by instrumented indentation testing. Carbon 81:505-513
36. Blatz PJ, Ko WL (1962) Application of finite elastic theory to the deformation of rubbery materials. Trans Soc Rheol 6:223-251

37. Abdi M, Ashcroft I, Wildman R (2018) Topology optimization of geometrically nonlinear structures using an evolutionary optimization method. Eng Optim 50(11):1850-1870

38. Hartmann S (2005) A remark on the application of the NewtonRaphson method in non-linear finite element analysis. Comput Mech 36(2):100-116

39. Jenco JM, Hunt ES (2000) Generic issues effecting SWG performance. Int J Pressure Vessel Pip 77:825-830

Publisher's Note Springer Nature remains neutral with regard to jurisdictional claims in published maps and institutional affiliations. 